\title{
Rheological evaluation of the fabrication parameters of cellulose acetate butyrate membrane on $\mathrm{CO}_{2} / \mathrm{N}_{2}$ separation performance
}

R J Lee ${ }^{1}$, Z A Jawad ${ }^{1 *}$, A L Ahmad², H B Chua ${ }^{1}$, H P Ngang², S H S Zein ${ }^{3}$

${ }^{1}$ School of Engineering and Science, Department of Chemical Engineering, Curtin University Malaysia, CDT 250, Miri 98009, Sarawak, Malaysia

${ }^{2}$ School of Chemical Engineering, Engineering Campus, Universities Sains Malaysia, 14300 Nibong

Tebal, Penang, Malaysia

${ }^{3}$ Chemical Engineering, School of Engineering and Computer Science, University of Hull, Hull, HU6 7RX, United Kingdom.

*Corresponding author: zeinab.aj@curtin.edu.my

Tel: +60 85443939 (2414), Fax: +60 85443837

This is the accepted manuscript of a book chapter published in Jawad, Z. (Ed.). (2019). Membrane Technology for CO2 Sequestration. Boca Raton: CRC Press, https://doi.org/10.1201/b22409 
2 The rise in emission of greenhouse gases (GHGs) mainly carbon dioxide $\left(\mathrm{CO}_{2}\right)$ in recent years due to

3 rapid development of modern civilisation, has been listed as the primary contributor to global warming.

4 To address this global issue, membrane technology was applied and developed intensively because of 5 its superior performance in terms of efficiency and economic advantages. In this study, the cellulose 6 acetate butyrate (CAB) polymer was selected as the polymer matrix material since it exhibited excellent 7 film-forming properties. In addition, the wet-phase inversion technique was adopted to synthesise the 8 membrane based on different casting conditions. The optimum outcomes of the fabrication conditions 9 were then characterised with the scanning electron micrograph (SEM) to determine the best CAB membrane for $\mathrm{CO}_{2} / \mathrm{N}_{2}$ separation. The results showed that CAB-70000 fabricated with $4 \mathrm{wt} \%$ of $\mathrm{CAB}$ 11 polymer concentration, casting thickness of $250 \mu \mathrm{m}$, solvent evaporation time of 5 minutes, and 30 minutes of solvent exchange for isopropyl alcohol and n-hexane, exhibited the best gas separation performance. Further, CAB-70000 showed an average selectivity of $6.12 \pm 0.09$ and permeance up to $14227.95 \pm 0.39$ GPU for $\mathrm{CO}_{2}$ and $37.28 \pm 0.54$ GPU for $\mathrm{N}_{2}$, respectively. In summary, this study is 15 expected to show a detailed outline of the future direction and perspective of the novel CAB polymeric 16 membrane that is suitable to be applied in the industry, and serves as an insight for researchers and 17 manufacturers working in the related field of gas separation. 


\subsection{Introduction}

There is a trend of rapid increase in world population, which is expected to hit 10 billion by 2050 (Lalia et al., 2013). In this regard, higher demand in energy will be required for the 21st century to meet the urgent needs. It is predicted that the energy demand will increase by 57 per cent in 2030 (Conti et al., 2016). As a major contributor to the world energy supply, fossil fuel solely contribute around 40 per cent of the total carbon dioxide $\left(\mathrm{CO}_{2}\right)$ emission into the environment, which is mainly attributed to the massive coal combustion activities (Carapellucci and Milazzo, 2003). Global warming has become a genuine problem due to the excessive discharge of pollutants emitted from the combustion activities in the primary industries (Yang et al., 2008).

In the past few decades through their efforts, researchers have contributed in combating this global issue to limit and minimise the impact of greenhouse gases (GHGs). They have outlined three feasible options. The first comprises of saving energy used intensively with methods that are more efficient. The second option is to minimise the usage of carbon-based material source or replace it with renewable energy, and the third is to improve the effectiveness of $\mathrm{CO}_{2}$ sequestration with more advanced technology development (Yang et al., 2008). For the past few years, membrane separation technology has been utilised intensively for both water treatment and gas separation purpose (Yang et al., 2008, Kappel et al., 2014, Barnes et al., 2014, Zhu et al., 2014). The membrane’s chemical and physical properties, and interaction between permeance and membrane are relatively crucial factors in determining the diffusion characteristics of the gas separation field (Shekhawat, 2003). This is because the separation selectivity and permeance are two critical parameters that indicate membrane separation performance. In an ideal situation, high selectivity and permeance are preferred as both induce less capital costs and operating expenses for the industries (Paradise and Goswami, 2007, Low et al., 2013). Hence, the selection of material plays an influential role, in determining the specific gas separation performance (Lalia et al., 2013, Zha et al., 2015, Feng et al., 2015).

The cellulose acetate butyrate (CAB) possesses few interesting characteristics that include, filmforming properties, acetyl and butyryl functional groups, which can effectively improve and further expand the capacity of cellulose chain giving high sorption characteristic, as well as high impact, 
weather and chemical resistant (Feng et al., 2015, Basu et al., 2010, Kunthadong et al., 2015). The CAB was first investigated and studied by Sourirajan back in 1958, then followed by Manjikian and others in reverse osmosis (RO) separation (Wang et al., 1994). They reported that the CAB membrane owned high solute separation with tolerable membrane flux result, and also provided ease of fabrication as some pre-treatment was negligible (Ohya et al., 1980, Wang et al., 1994). However, limited studies have been conducted on the effects of the acetyl group content on $\mathrm{CAB}$ membranes in the $\mathrm{CO}_{2} / \mathrm{N}_{2}$ gas separation field. Further, no reports or systematic studies have been performed on the effects of membrane production procedure and fabrication parameters. This includes membrane-casting thickness, solvent exchange time for both isopropyl alcohol and n-hexane with different CAB molecular weights as well as the polymer matrix material structure and performance of CAB membranes. Therefore, the primary objective of this study is to investigate the effects of membrane production procedure and fabrication parameters. Discussions on how the mentioned parameters can affect the membrane in terms of morphology and gas separation performance are presented in this report. The separation performance of the synthesised CAB membrane was selected to evaluate the specified parameters towards $\mathrm{CO}_{2} / \mathrm{N}_{2}$.

\subsection{Methodology}

\subsection{Materials}

The cellulose acetate butyrate (CAB, $\left.M_{\mathrm{n}} \sim 12000,65000,70000\right)$ in powder form was purchased from Sigma-Aldrich (Malaysia) for membrane preparation. Solutions required for membrane preparation i.e., chloroform, isopropyl alcohol, and n-hexane were purchased from Merck (Malaysia). Distilled water was used for the phase-inversion steps, specifically for immersion precipitation for membrane formation.

\subsection{CAB Polymer dope preparation}

The CAB membrane was prepared using the wet-phase inversion method, followed by solvent exchange to dry the membrane. A dope solution consisting of $4 \mathrm{wt} \% \mathrm{CAB}(M n=70000)$ powders and $96 \mathrm{wt} \%$ chloroform was prepared following the condition of each parameter. The solution was stirred for 24 hours, and then sonicated for 20 minutes to eliminate the gas bubbles in the solution (Ahmad et al., 2014, Feng et al., 2015). The solution was then poured into space within the casting bars with glass plate 
underneath. An automatic film applicator (Elcometer 4340, E.U.) was then used for the casting of the membrane. Referring to our previous work, 5 minutes of solvent evaporation time was allowed following each parameter's condition before immersing the membrane in distilled water $\left(27^{\circ} \mathrm{C}\right)$ for a duration of 24 hours (S.Minhas, 1992, Lee et al., 2017). The solvent exchange was performed on the asspun membrane first with 60 minutes immersion period in isopropyl alcohol and then another 60 minutes immersion period in n-hexane. The resultant membrane was then dried at ambient temperature to eliminate the remaining volatile liquid in between two glass plates filled with filter paper for 24 hours before use (S.Minhas, 1992, Jawad et al., 2015a)

\subsubsection{Effect of casting thickness}

The membranes were prepared at different casting thicknesses following the fabrication method as described in section 2.2 where the study range for this parameter was from $200 \mu \mathrm{m}$ (CAB-200), $250 \mu \mathrm{m}$ (CAB-250) to $300 \mu \mathrm{m}(\mathrm{CAB}-300)$.

\subsubsection{Effect of exchange time with isopropyl alcohol}

Meanwhile, for the effect of solvent exchange time, the membranes were prepared following the fabrication method as described in section 2.2. The solvent exchange duration studied was 15 minutes (CAB-15Iso), 30 minutes (CAB-30Iso), and 60 minutes (CAB-60Iso) for isopropyl alcohol, followed by 60 minutes of n-hexane.

\subsubsection{Effect of exchange time with n-hexane}

In addition, the solution of the solvent exchange time with n-hexane was prepared following the fabrication method as described in section 2.2. The resultant membranes were first solvent exchanged with isopropyl alcohol for 30 minutes followed by solvent exchange times ranging from 15 minutes (CAB-15H), 30 minutes (CAB-30H) to 60 minutes (CAB-60H) for n-hexane.

\subsubsection{Effect of CAB at different molecular weight $\left(M_{n}\right)$}

The membranes were prepared with different CAB molecular weights $\left(M_{\mathrm{n}}\right)$ of 12000 (CAB-12000), 65000 (CAB-65000), and 70000 (CAB-70000) for the preparation of the dope solution. After that, following the fabrication method as mentioned in section 2.2, the solvent exchange time for isopropyl alcohol and n-hexane were set for 30 minutes each. 


\subsection{Membrane permeability test}

The procedure for gas permeation measurement was discussed in our previous published work (Lee et al., 2017).

\subsection{Membrane characterization}

\subsubsection{Scanning Electron Microscopy (SEM)}

The CAB membrane structures including surface and cross-sectional, were observed via SEM (Hitachi TM3000, Tokyo, Japan). Each membrane sample was cut into small pieces, and then kept on a plastic petri dish in the cryogenic freezer at a temperature of up to $-80^{\circ} \mathrm{C}$ for 24 hours to give a consistent and clean-cut by freezing. The samples were coated with a platinum layer to prevent high-energy beam damage before the characterisation works. Further, each sample's average membrane thickness was calculated based on the frequency count as measured by the Image-J software. Approximately, 100 measurements were taken to confirm the average membrane thickness.

\subsubsection{X-ray Photoelectron Spectroscopy (XPS)}

The $\mathrm{CAB}$ membranes fabricated at different molecular weights were characterised with the High Resolution Multi-Technique X-Ray Spectrometer (Axis Ultra DLD XPS, Kratos, Shimadzu Corporation, Japan). The analysis was carried out using a PHI 1600 spectrometer with hybrid lens mode, $150 \mathrm{~W}$ (Anode: Mono), $1000 \mathrm{meV}$ step, and 5 sweeps for each membrane at room temperature.

\subsection{Results and Discussion}

\subsection{Effect of casting thickness}

The effect of casting thickness on the structure and performance of the CAB membrane was investigated, as depicted in Fig. 1. As observed from Fig. 1a, the structure of CAB-200 (200 $\mu \mathrm{m})$ was porous. As the casting thickness of the membranes increased, a smooth surface was observed for CAB-250 $(250 \mu \mathrm{m})$, as demonstrated in Fig. 1c. Alternatively, a rough surface was formed for CAB-300 (250 $\mu \mathrm{m})$, as seen in Fig. 1e. The change in the structure was due to the different rates of demixing that occurred as the phase precipitation proceeded when high casting thickness was applied, causing the deposition speed of the membrane to reduce during the membrane formation phase. The slow deposition rate avoids rapid 
135

136

exchange of non-solvent and solvent within the membrane. As a result, the surface structure of the CAB membrane was built-up based on the sufficient phase precipitation period given (Ahmad et al., 2013, Thomas et al., 2014).

The cross-sectional micrographs of the fabricated CAB membrane at casting thickness of $200 \mu \mathrm{m}$ (CAB-200), $250 \mu \mathrm{m}$ (CAB-250), and $300 \mu \mathrm{m}$ (CAB-300) were revealed in Figs. 1b, d, and f, respectively. From the micrographs, dense structures were depicted from all the cross-sectionals of the CAB membranes. The dense structure formation was due to the densification of the membrane during the immersion period, whereby the remaining solvent imbedded in the polymer matrix was replaced by distilled water. As the volatility of the solvent was generally higher than distilled water the membrane thickness changed from $12.42 \pm 0.05 \mu \mathrm{m}$ to $11.32 \pm 0.06 \mu \mathrm{m}$ and $12.89 \pm 0.10 \mu \mathrm{m}$ for CAB-200, CAB250 and CAB-300, respectively. The reduction of membrane thickness from $12.42 \pm 0.05 \mu \mathrm{m}$ (CAB200) to $11.32 \pm 0.06 \mu \mathrm{m}(\mathrm{CAB}-250)$ was due to thicker casting thickness applied during membrane fabrication, which allows more solvent embedded in the polymer matrix to be replaced by non-solvent $\left(\mathrm{H}_{2} \mathrm{O}\right)$ during the immersion period, resulting in a denser and thinner membrane thickness for CAB-250 (Ahmad et al., 2013). In contrast, a thicker membrane was obtained when increasing the membrane thickness further to $300 \mu \mathrm{m}$ for CAB-300 $(12.89 \pm 0.10 \mu \mathrm{m})$. This is correlated to the increase resistance of inward diffusion of non-solvent, due to higher casting thickness applied, causing a delay transition demixing in the film membrane (Tiraferri et al., 2011).
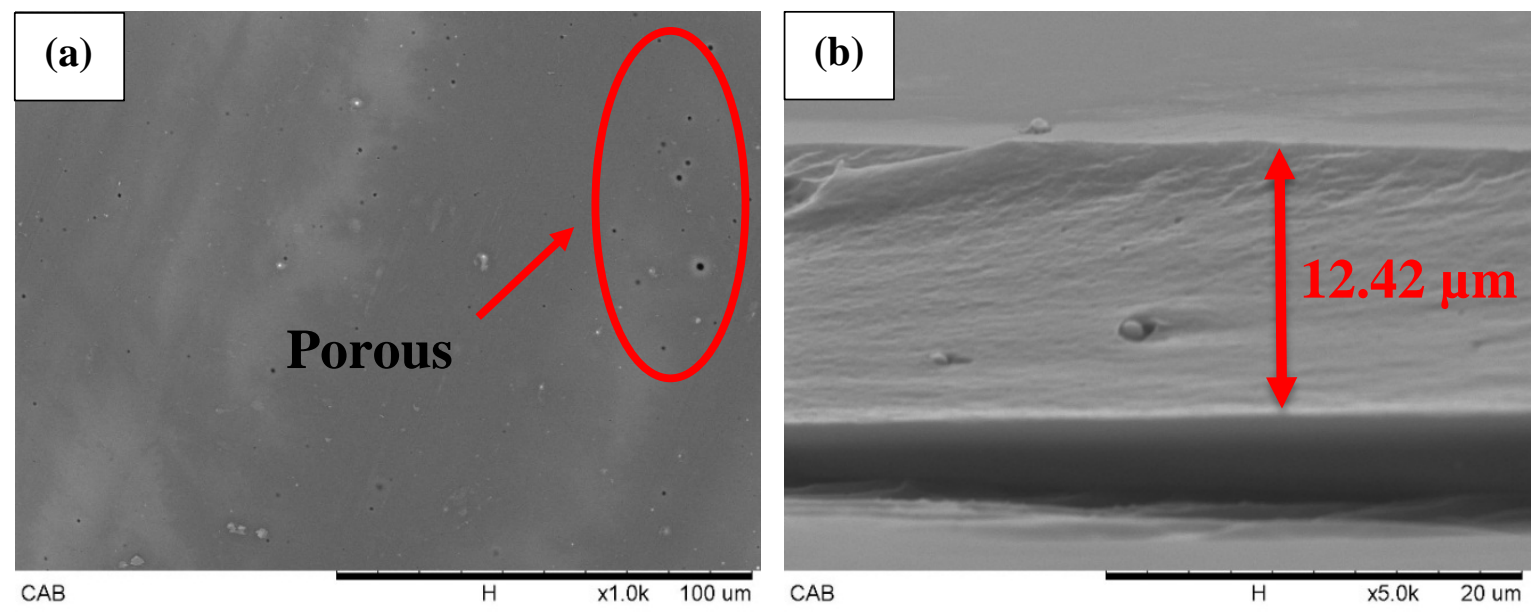

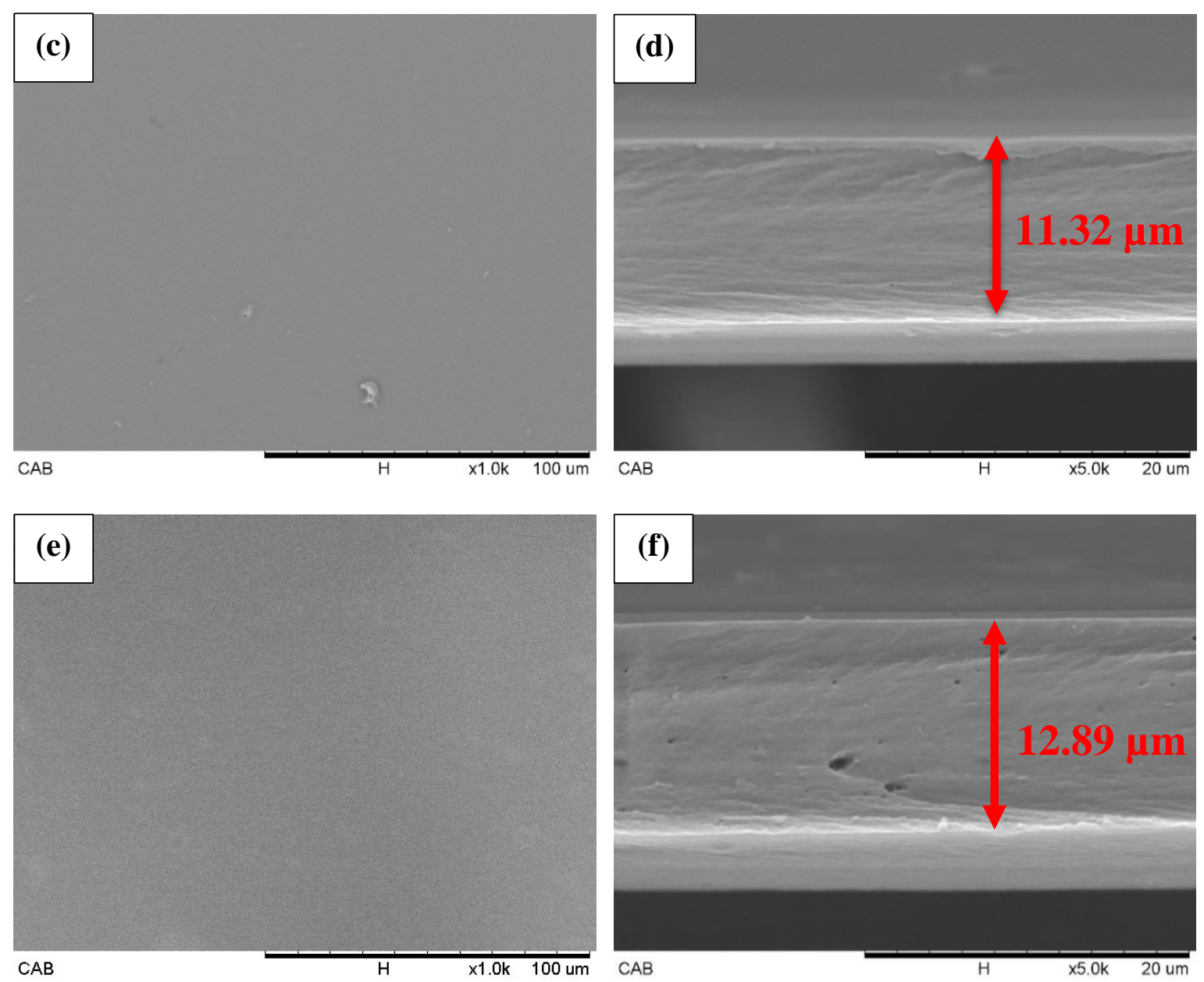

Fig 1. Top and cross-sectional SEM of CAB membrane at casting thickness (a-b) $200 \mu \mathrm{m}$ (CAB200), (c-d) $250 \mu \mathrm{m}$ (CAB-250), and (e-f) $300 \mu \mathrm{m}$ (CAB-300), with $4 \mathrm{wt} \%$ CAB polymer concentration and 5 minutes solvent evaporation time

The $\mathrm{CO}_{2}$ permeance of CAB-200, CAB-250, and CAB-300 are illustrated in Fig. 2. Notably,

CAB-250 demonstrated a higher permeance result of $398.46 \pm 1.43 \mathrm{GPU}$, as compared to CAB-200

$(143.03 \pm 0.62 \mathrm{GPU})$ and CAB-300 $(12.93 \pm 0.34 \mathrm{GPU})$. This was because of the reduction in its membrane thickness (11.32 $\mu$ m, Fig. 1d) and its selective smooth surface structure, which allowed the solution diffusion mechanism to occur efficiently. Therefore, the $\mathrm{CO}_{2}$ permeance of CAB-250 increased (Jawad et al., 2015a). Meanwhile, the $\mathrm{CO}_{2}$ permeance of CAB-300 reduced to $12.93 \pm 0.34 \mathrm{GPU}$,

160 indicating that a higher casting thickness beyond $250 \mu \mathrm{m}$ can exert extra resistance towards gas diffusion

161 within the membrane, which in turn affects the efficiency of gas permeation due to the thick dense

162 membrane synthesised (Fig. 1f). 


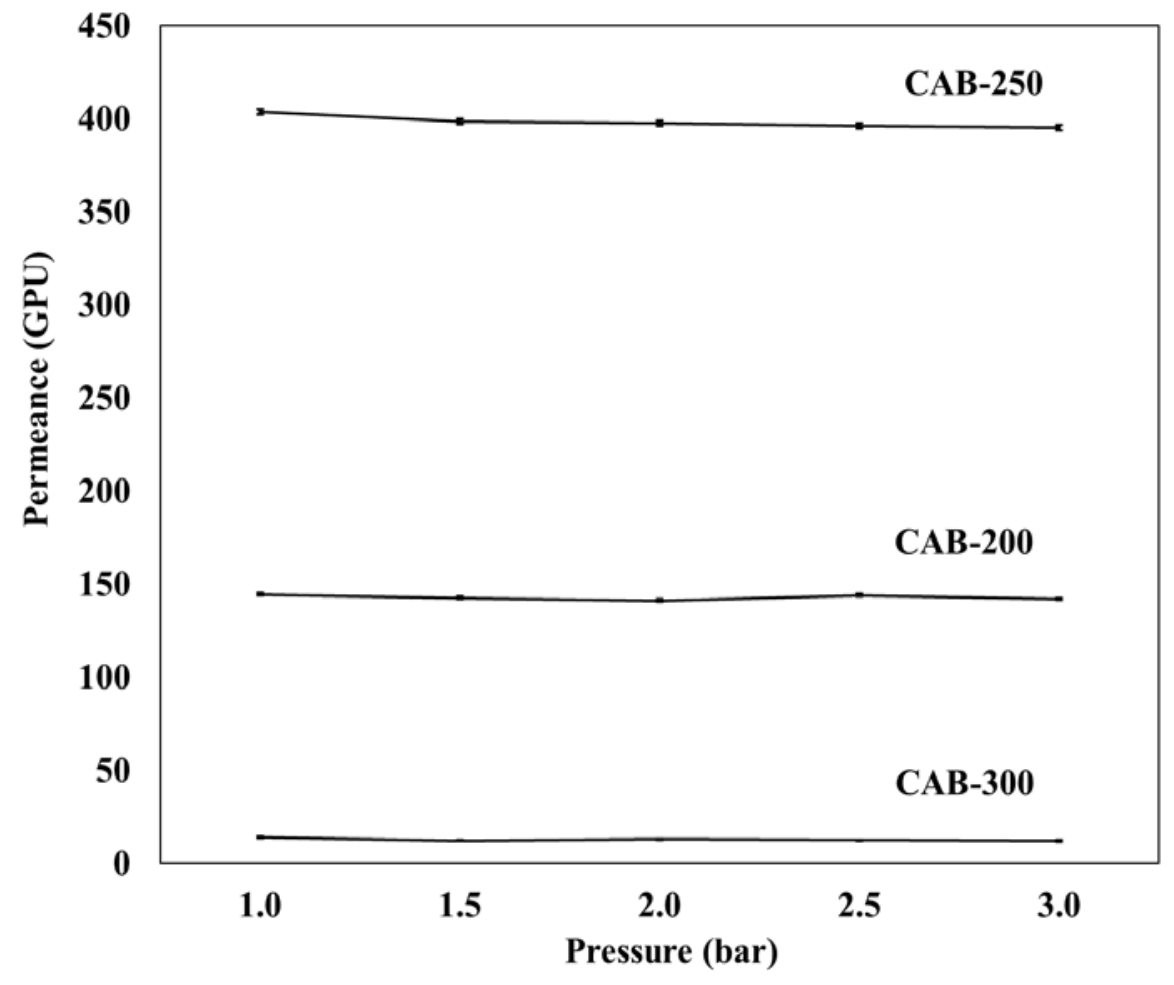

Fig 2. $\mathrm{CO}_{2}$ permeance for membrane fabricated at $200 \mu \mathrm{m}$ (CAB-200), $250 \mu \mathrm{m}$ (CAB-250), and $300 \mathrm{\mu m}$ (CAB-300), with $4 \mathrm{wt} \%$ CAB polymer concentration and 5 minutes solvent evaporation time

163

164

165

166

On the other hand, the $\mathrm{N}_{2}$ permeance for CAB-200, CAB-250 and CAB-300 were $112.83 \pm 0.85$, $121.55 \pm 1.30$, and $11.26 \pm 0.31$ GPU, respectively, as illustrated in Fig. 3. The CAB-250 exhibited higher $\mathrm{N}_{2}$ permeance results. This was due to the initial casting thickness applied, resulting in a smooth membrane structure, which created less resistance towards the permeance of $\mathrm{N}_{2}$ gas within the membrane (Freeman, 1999). The low $\mathrm{N}_{2}$ permeance result yield for CAB-300 (11.26 $\left.\pm 0.31 \mathrm{GPU}\right)$ was due mainly to the thick dense membrane structure $(12.89 \pm 0.10 \mu \mathrm{m})$, which ultimately governed the solution diffusion rate of the membrane, as a thicker membrane usually induces more resistance to gas diffusion (Koros et al., 1988a). 


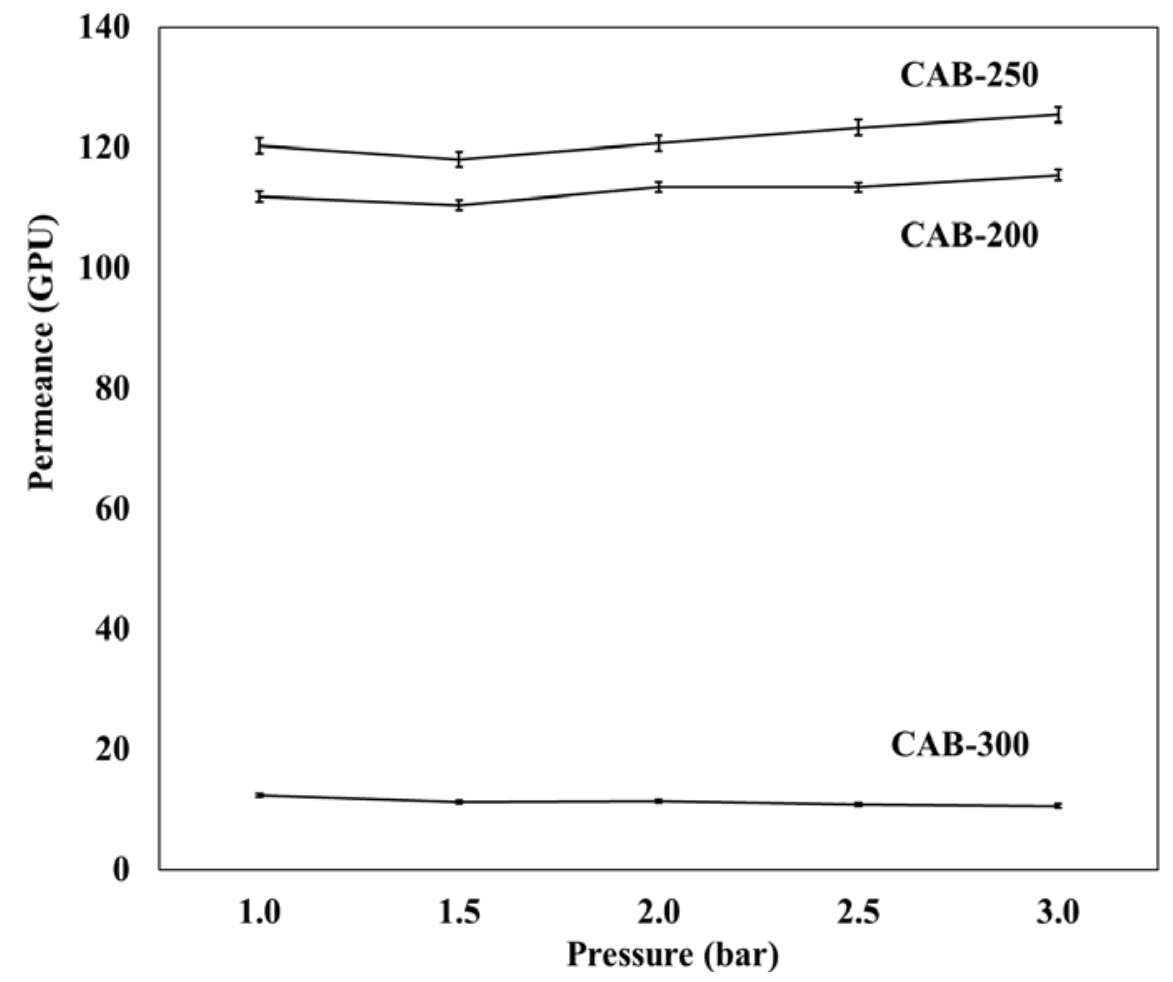

Fig 3. $\mathrm{N}_{2}$ permeance for membrane fabricated at $200 \mu \mathrm{m}$ (CAB-200), $250 \mu \mathrm{m}$ (CAB-250), and $300 \mathrm{\mu m}(\mathrm{CAB}-300)$, with $4 \mathrm{wt} \%$ CAB polymer concentration and 5 minutes solvent evaporation time

172

The ideal selectivity of $\mathrm{CO}_{2} / \mathrm{N}_{2}$ separation performance for CAB-200, CAB-250, and CAB-300

175 to $250 \mu \mathrm{m}$ the selectivity increased from $1.27 \pm 0.01 \mathrm{GPU}$ (CAB-200) to $3.28 \pm 0.04 \mathrm{GPU}$ (CAB-250).

176 The acceptable result obtained for CAB-250 was due to the membrane structure formation, which

177 eventually increased the $\mathrm{CO}_{2}$ permeance against the $\mathrm{N}_{2}$ permeance attained. However, the selectivity

178 reduced to $1.15 \pm 0.01 \mathrm{GPU}$ when the higher casting thickness $(300 \mu \mathrm{m})$ was implemented for CAB-

179 300. Even though the thickness of the membrane was essential for effective gas separation, however, excessive membrane thickness restricted the gas diffusion within the membrane. 


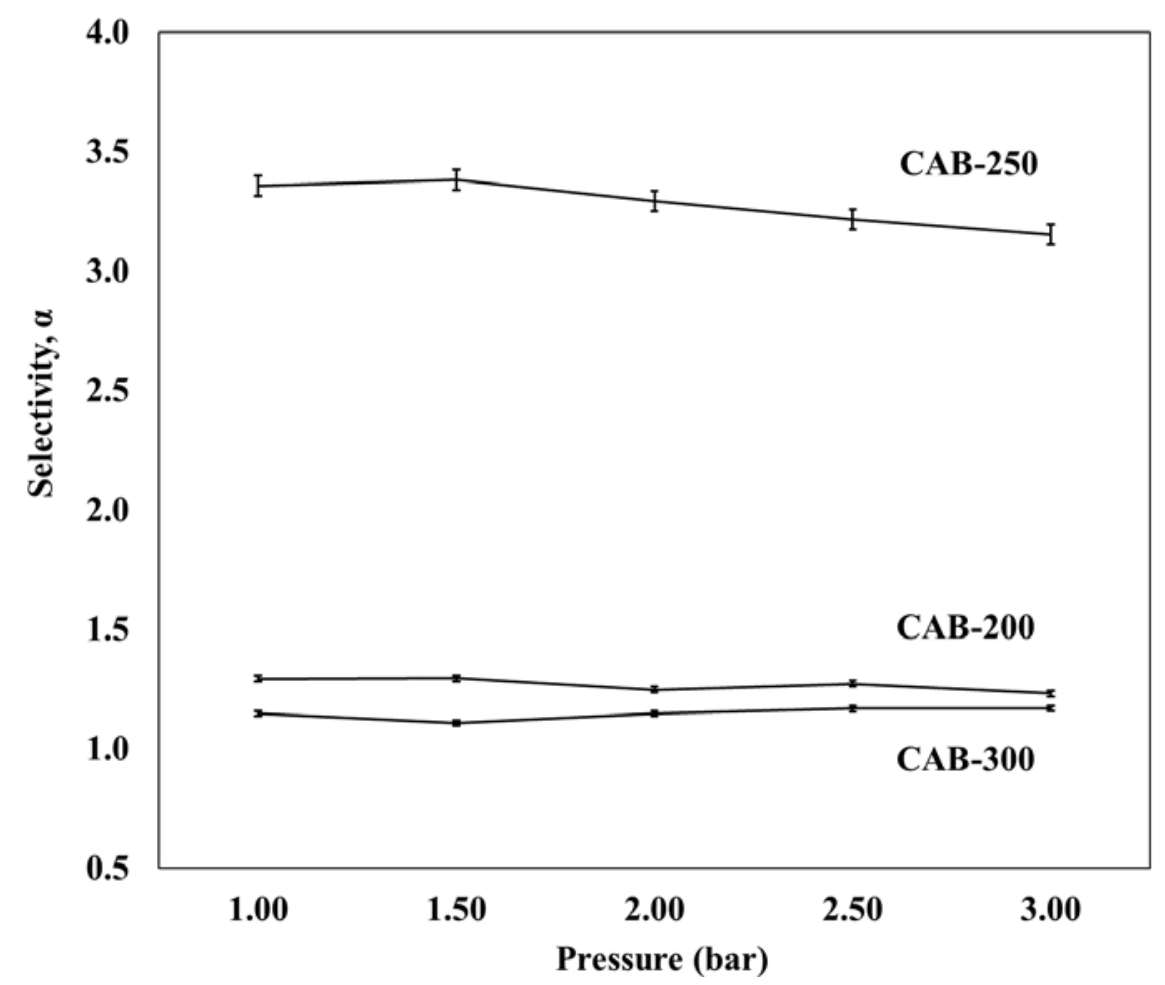

Fig 4. Ideal selectivity of $\mathrm{CO}_{2} / \mathrm{N}_{2}$ for membranes fabricated at different casting thickness $200 \mathrm{~m}$ (CAB-200), $250 \mu \mathrm{m}$ (CAB-250), and $300 \mu \mathrm{m}$ (CAB-300), with 4 wt\% CAB polymer concentration and 5 minutes solvent evaporation time

181

182

183

184

185

\subsection{Effect of solvent exchange with Isopropyl alcohol}

The solvent exchange was performed after the precipitation immersion process of the CAB membrane with the purpose of drying or removing any remaining volatile liquid in the membrane. As displayed in Figs. 5a and $\mathbf{b}$, the CAB-15Iso (15 minutes) exhibited a porous surface and irregular dense crosssectional structure with a membrane thickness of $13.87 \pm 0.23 \mu \mathrm{m}$. This porous structure surface was caused by the rapid solvent exchange between the water molecules available within the CAB structure and the first solvent (isopropyl alcohol) (Lui et al., 1988). During the first step of the solvent exchange process, an enormous amount of water molecules embedded in the membrane were generally replaced by isopropyl alcohol. As a result, due to the short 15 minutes solvent exchange immersion period allocated, vigorous pore formation appeared throughout the film membrane of CAB-15Iso (Lui et al., 1988). Thus, CAB-15Iso demonstrated thick membrane thickness because of the short solvent exchange time applied, resulting in more water molecules retaining inside the membrane. 
196 (CAB-30Iso) and then subsequently to 60 minutes (CAB-60Iso), both revealed a smooth surface (Figs.

$1975 \mathbf{c}$ and $\mathbf{e}$ ) with thin dense membrane thickness of $9.45 \pm 0.06 \mu \mathrm{m}$ and $9.30 \pm 0.05 \mu \mathrm{m}$, respectively, as

198 demonstrated in Figs. 5d and $\mathbf{f}$. The formation of smooth surface and thin membrane was because of the

199 longer immersion period allocated. Therefore, this provided more relaxation time for the non-solvent

$200\left(\mathrm{H}_{2} \mathrm{O}\right)$ imbedded in the film membrane to exchange with the isopropyl alcohol (Radjabian et al., 2014).

201 This also allowed the formation of a thin dense membrane with homogeneous smooth surface structure 202 as revealed from CAB-30Iso and CAB-60Iso.

203
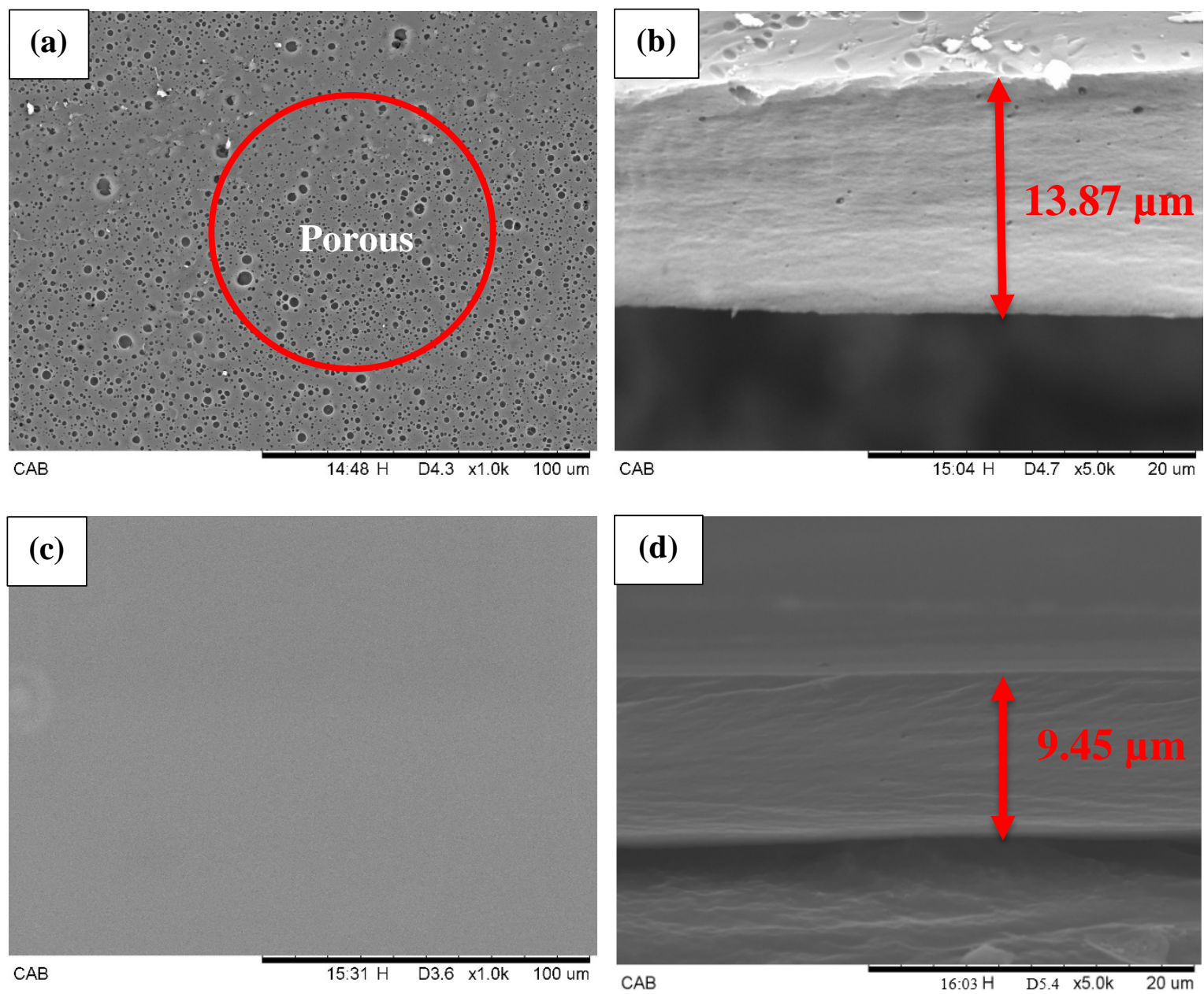

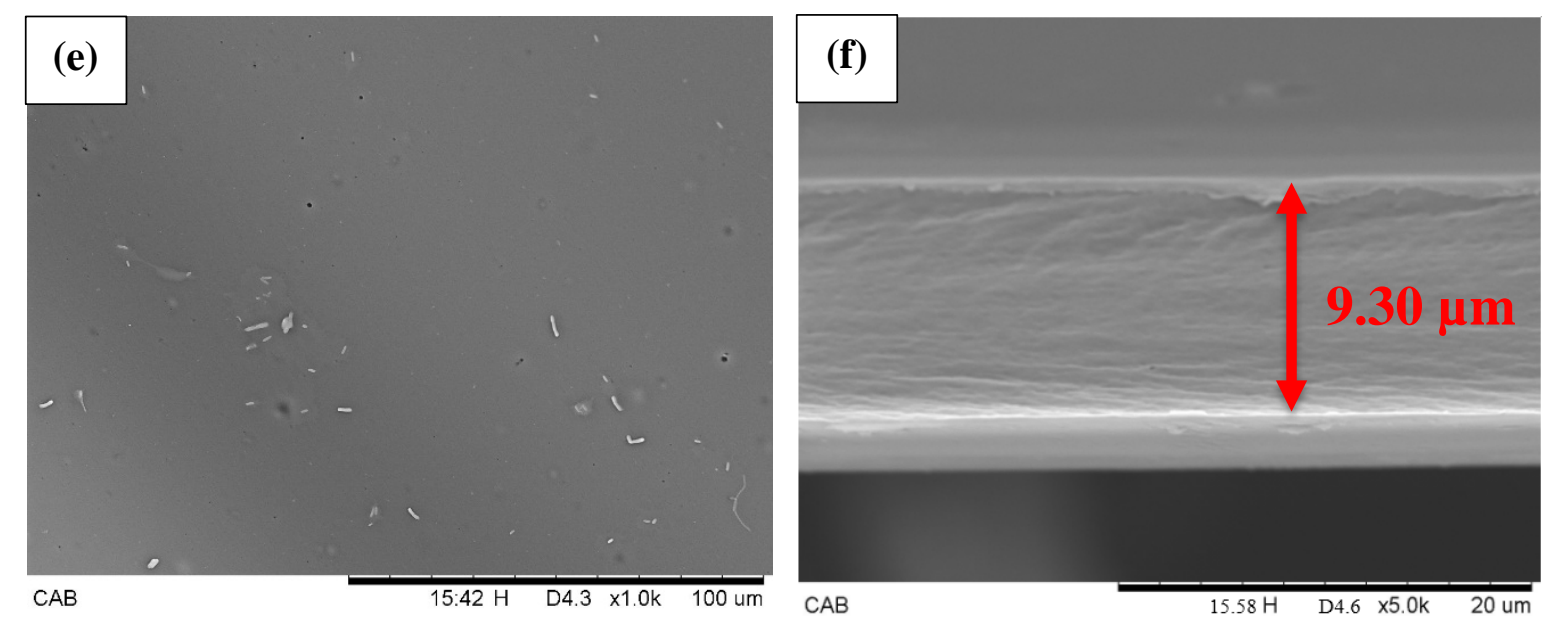

Fig 5. Surface and cross-sectional SEM of CAB membrane dried with isopropyl alcohol first for a solvent exchange duration of (a-b) 15 minutes (CAB-15Iso), (c-d) 30 minutes (CAB-30Iso), and (e-f) 60 minutes (CAB-60Iso); then subsequently solvent exchanged with 60 minutes of $\mathrm{n}$-hexane as the final solvent, at casting thickness of $250 \mu \mathrm{m}$ and 5 minutes solvent evaporation time

As shown in Fig. 6, the $\mathrm{CO}_{2}$ permeance rates increased from $65.53 \pm 0.34$ GPU (CAB-15Iso) to 262.29 $\pm 0.16 \mathrm{GPU}$ (CAB-30Iso) and increased further to $398.82 \pm 0.94$ GPU (CAB-60Iso) by changing the solvent exchange duration of isopropyl from 15 minutes to 30 minutes and subsequently to 60 minutes, respectively. This resulted in extensive water content reduction within the membrane structure due to longer immersion period allocated. The steady exchange rate of water with isopropyl alcohol within the $\mathrm{CAB}$ polymer matrix caused less $\mathrm{CO}_{2}$ molecules to interact with the water, therefore allowing more $\mathrm{CO}_{2}$ gas to permeate through the membrane (Jawad et al., 2015b). In the meantime, the high $\mathrm{CO}_{2}$ permeance rate for CAB-60Iso (60 minutes) contributed to the thin dense membrane structure, which allowed the $\mathrm{CO}_{2}$ feed gas to pass through the membrane with least resistance pathway as compared to the thick dense membrane (Tiraferri et al., 2011). Thus, the CAB-60Iso (60 minutes) yielded the highest $\mathrm{CO}_{2}$ permeance rate amongst the other membranes (CAB-15Iso and CAB-30Iso). 


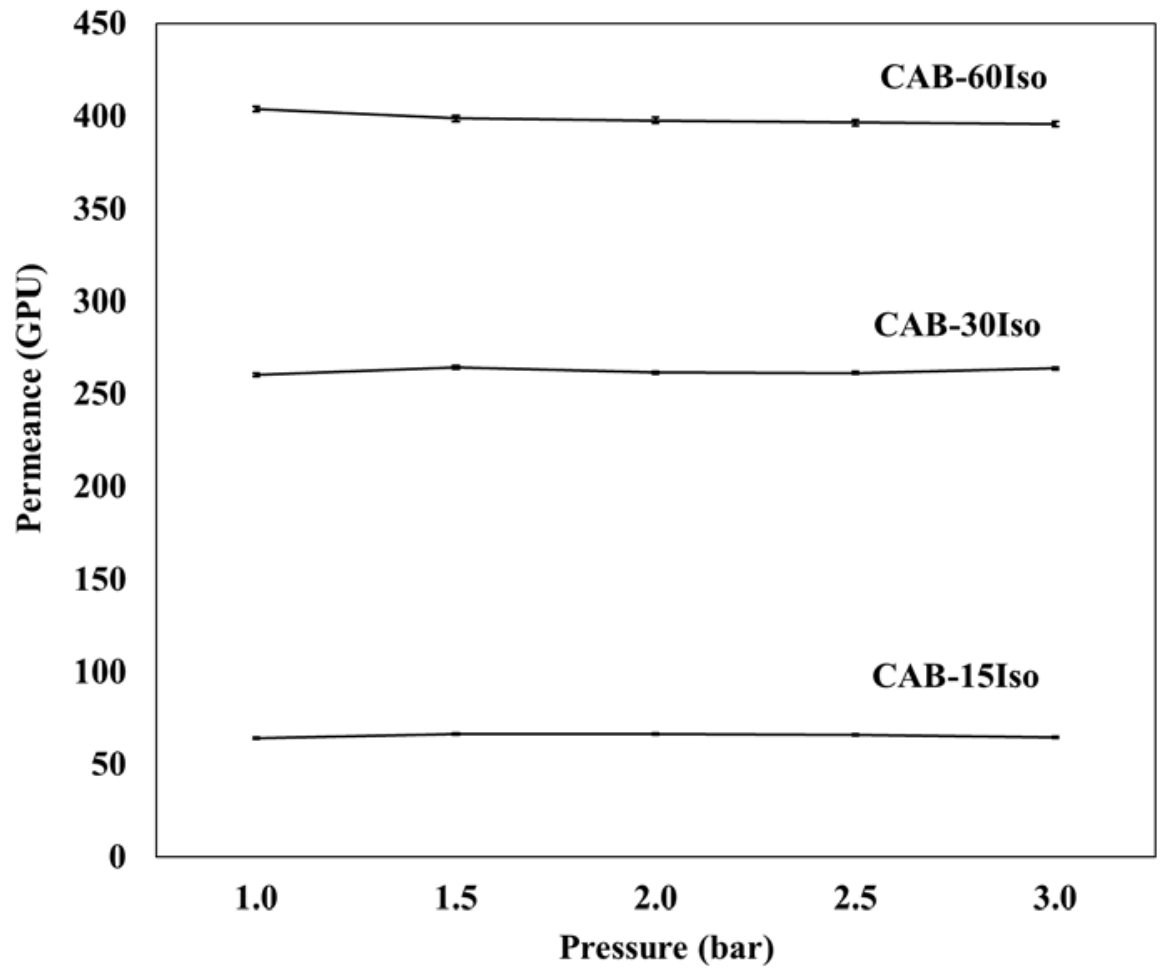

Fig 6. $\mathrm{CO}_{2}$ permeance for membrane dried with 15 minutes (CAB-15Iso), 30 minutes (CAB30Iso), and 60 minutes (CAB-60Iso) of isopropyl alcohol; then subsequently solvent exchanged with 60 minutes of $n$-hexane as the final solvent, at casting thickness of $250 \mu \mathrm{m}$ and 5 minutes solvent evaporation time

The $\mathrm{N}_{2}$ permeance rates for CAB-15Iso, CAB-30Iso, and CAB-60Iso are depicted in Fig. 7. The results obtained for $\mathrm{N}_{2}$ permeance were $64.59 \pm 0.41,70.49 \pm 0.33$, and $121.76 \pm 0.83$ GPU for CAB-

224 15Iso, CAB-30Iso, and CAB-60Iso, respectively. The possible explanation for this trend was due to the 225 reduction in the membrane thickness from $13.87 \mu \mathrm{m}$ to $9.3 \mu \mathrm{m}$ (Fig. 5). In addition, as isopropyl alcohol 226 was mainly made up from non-polar molecules, the remaining molecules within the CAB structure can 227 easily attract light gas molecules (Katayama and Nitta, 1976). Thus, with longer solvent exchange 228 duration, more isopropyl alcohol was retained within the polymer matrix, hence, attracting more $\mathrm{N}_{2}$ gas 229 molecules and resulting in the high $\mathrm{N}_{2}$ permeance rate for CAB-60Iso (60 minutes). Eventually as the 230 solvent exchange duration decreased, the $\mathrm{N}_{2}$ permeance rate for CAB-15Iso and CAB-30Iso reduced as 231 well. 


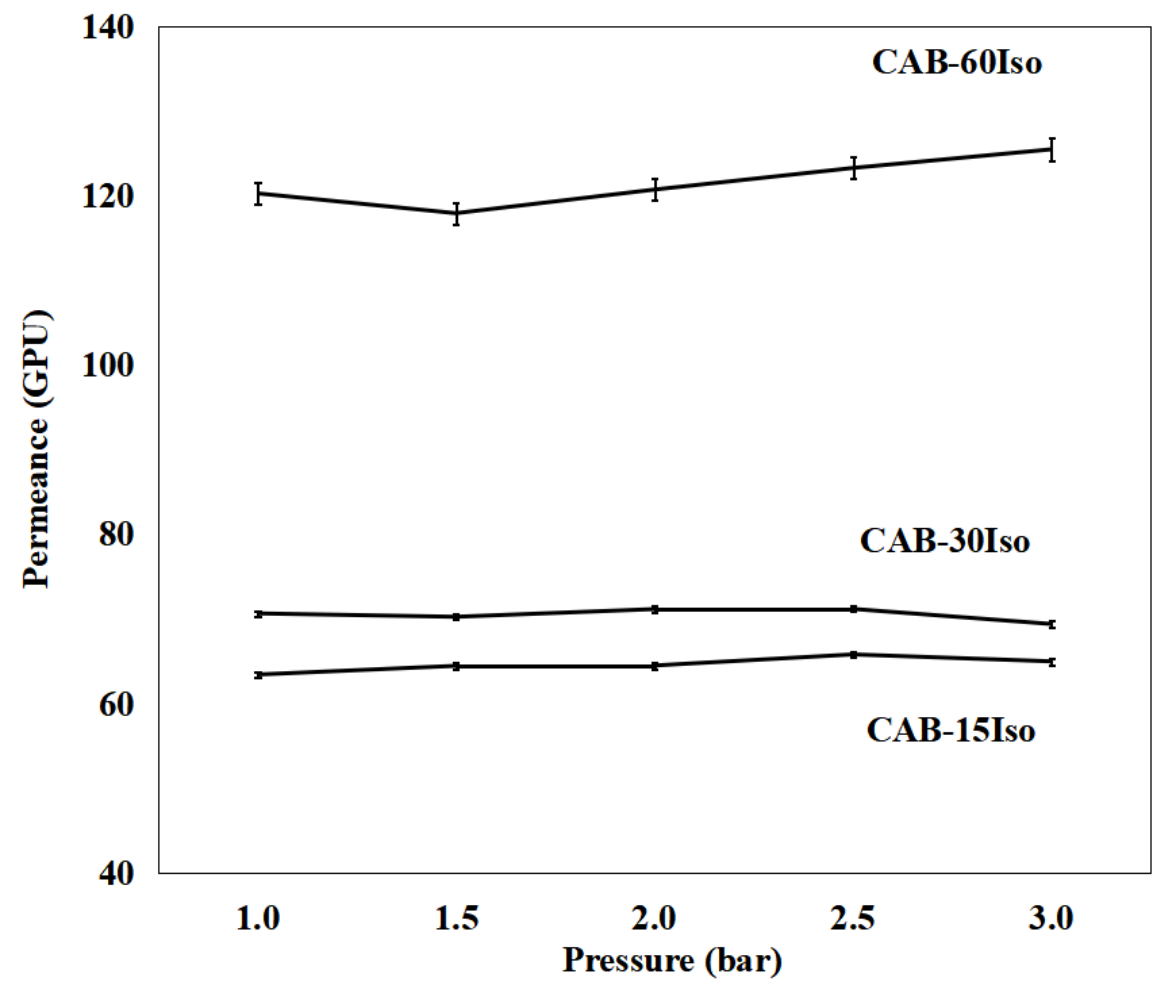

Fig 7. $\mathrm{N}_{2}$ permeance for membrane dried with 15 minutes (CAB-15Iso), 30 minutes (CAB30Iso), and 60 minutes (CAB-60Iso) of isopropyl alcohol; then subsequently solvent exchanged with 60 minutes of $n$-hexane as the final solvent, at casting thickness of $250 \mu \mathrm{m}$ and 5 minutes solvent evaporation time

As discussed previously, CAB-60Iso (60 minutes) showed a thin dense membrane formation with high $\mathrm{CO}_{2}$ and $\mathrm{N}_{2}$ permeance rates. However, based on Fig. 8, the CAB-30Iso (30 minutes) yielded the

234 best selectivity performance. This was due to the smooth homogeneous surface and superior cross-

235 sectional morphology, which selectively allowed a predetermined amount of $\mathrm{CO}_{2}$ and $\mathrm{N}_{2}$ to pass through

236 the dense membrane. On the contrary, the CAB-15Iso (15 minutes) demonstrated low selectivity (Fig.

237 8). This was due to the presence of a thick irregular surface morphology (Figs. 5a and b), which imposed

238 an undesirable effect on membrane permeance performance due to extra resistance pathway generated 239 (Rahimpour et al., 2008, Yang and Wang, 2006). Therefore, CAB-30Iso (30 minutes) was preferred as compared to CAB-15Iso (15 minutes) and CAB-60Iso (60 minutes) because of its excellent morphology

241 and good selectivity performance. 


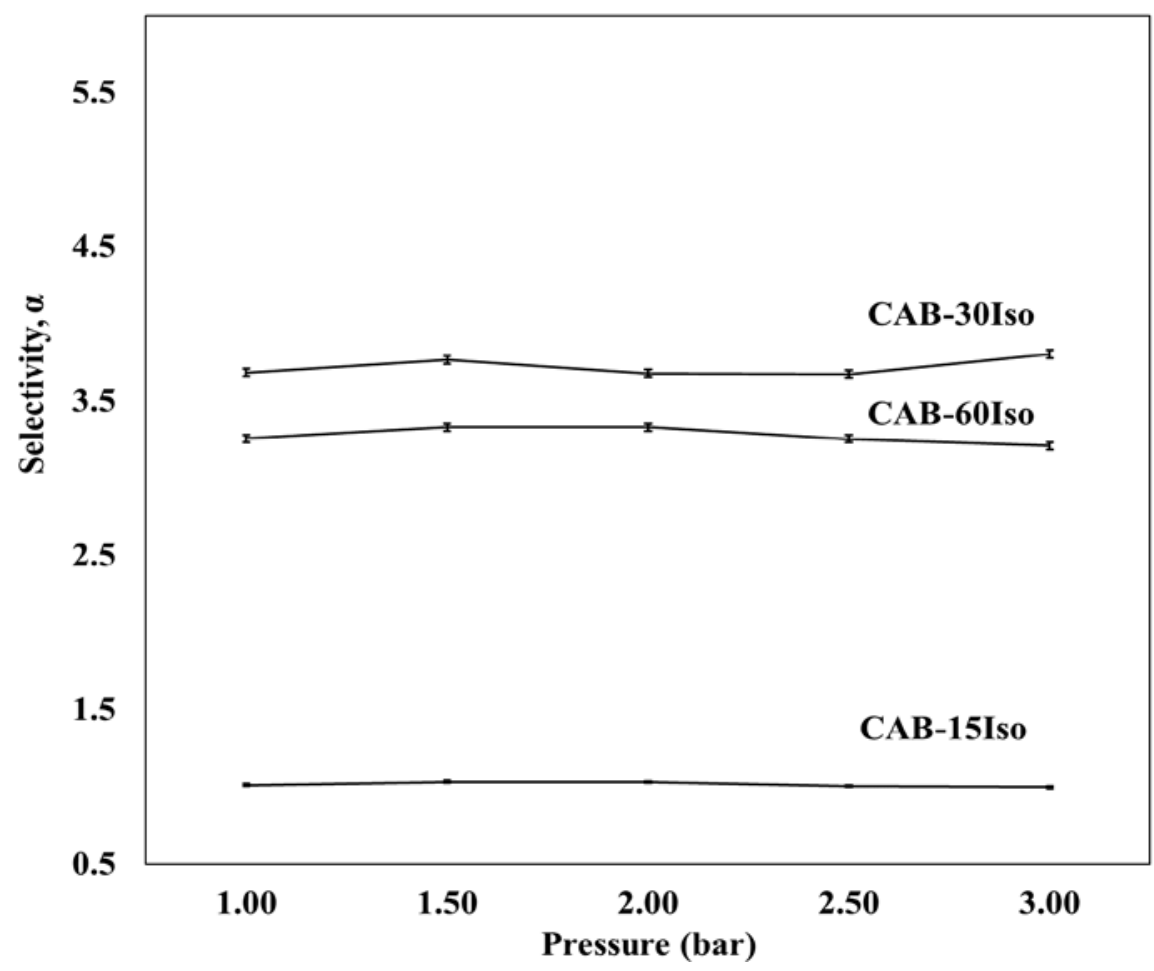

Fig 8. Ideal selectivity of $\mathrm{CO}_{2} / \mathrm{N}_{2}$ for membranes synthesised with solvent exchange duration of 15 minutes (CAB-15Iso), 30 minutes (CAB-30Iso), and 60 minutes (CAB-60Iso); then subsequently exchanged with 60 minutes of $n$-hexane as the final solvent, at casting thickness of $250 \mu \mathrm{m}$ and 5 minutes solvent evaporation time

\subsection{Effect of exchange time with n-hexane}

As discussed in the previous section, the best solvent exchange time for isopropyl alcohol was 30 minutes (CAB-30Iso). Subsequently, the CAB membrane was subjected to further optimisation with the drying time of n-hexane. In this study, the CAB membranes were dried with solvent exchange times of 24815 minutes (CAB-15H), 30 minutes (CAB-30H), and 60 minutes (CAB-60H) using n-hexane. As 249 revealed from the SEM image in Fig. 9, the surface of CAB-15H (15 minutes) exhibited a porous 250 structure, while CAB-30H (30 minutes) and CAB-60H (60 minutes) showed smooth surfaces. The main reason for the porous structure showed by CAB-15H was due to the rapid evaporation of the volatile solvent from the membrane structure itself and short duration of immersion period implemented (Chung and Kafchinski, 1997). Gradually by increasing the solvent exchange immersion period, the membrane

254 had sufficient time for the solvent exchange to occur between isopropyl alcohol and n-hexane at a 255 consistent and steady rate. Hence, suppressing a vigorous solvent exchange process within the polymer, 
resulted in a smooth homogeneous surface as observed for CAB-30H (30 minutes) and CAB-60H (60

257 minutes) (Choi et al., 2006).

As presented in Fig. 9, the membrane thickness for CAB-15H (15 minutes), CAB-30H (30

minutes), and CAB-60H (60 minutes) were $11.79 \pm 0.18,9.50 \pm 0.10$, and $9.45 \pm 0.06 \mu \mathrm{m}$, respectively.

260 As seen from these results, the increased exchange time of n-hexane caused the CAB membrane to

261 become more compact due to membrane densification as time passed (Sabde et al., 1997). In addition,

262 the main reason for the reduction in the membrane thickness was due to the isopropyl alcohol imbedded

263 within the membrane slowly being replaced by n-hexane with time. The replacement of isopropyl

264 alcohol with n-hexane occurred when the molecular affinity of n-hexane was greater than isopropyl

265 alcohol (Hansen, 2007). Referring to the Hansen solubility chart, the solubility for isopropyl alcohol, n-

266 hexane, and water are 23.6, 14.9, and 47.9 $\mathrm{MPa}^{1 / 2}$, respectively (Egan and Dufresne, 2008, Hansen,

267 2007). Therefore, the molecular affinity is in the order of CAB-water $>$ CAB-isopropyl alcohol $>$ CAB-n-

268 hexane. The order of the molecular affinity represents the attraction force between the polymer and the

269 solvent and non-solvent used (Kim and Oh, 2001).
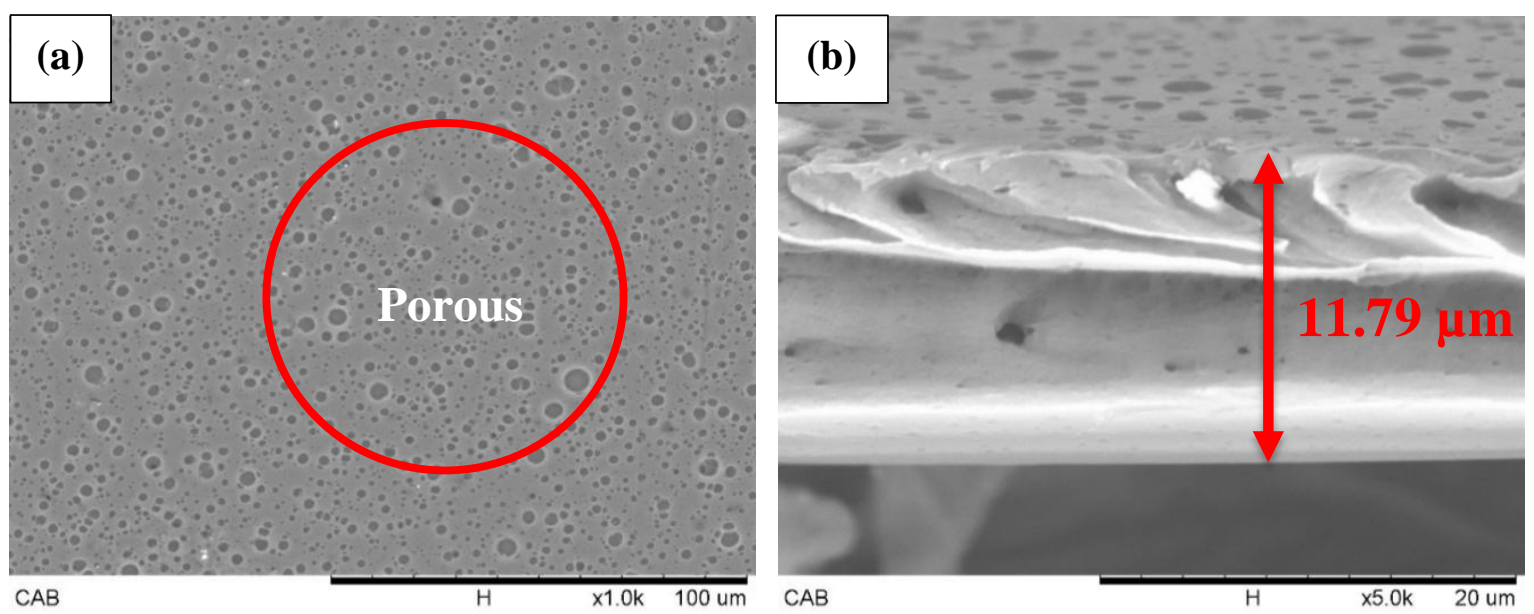

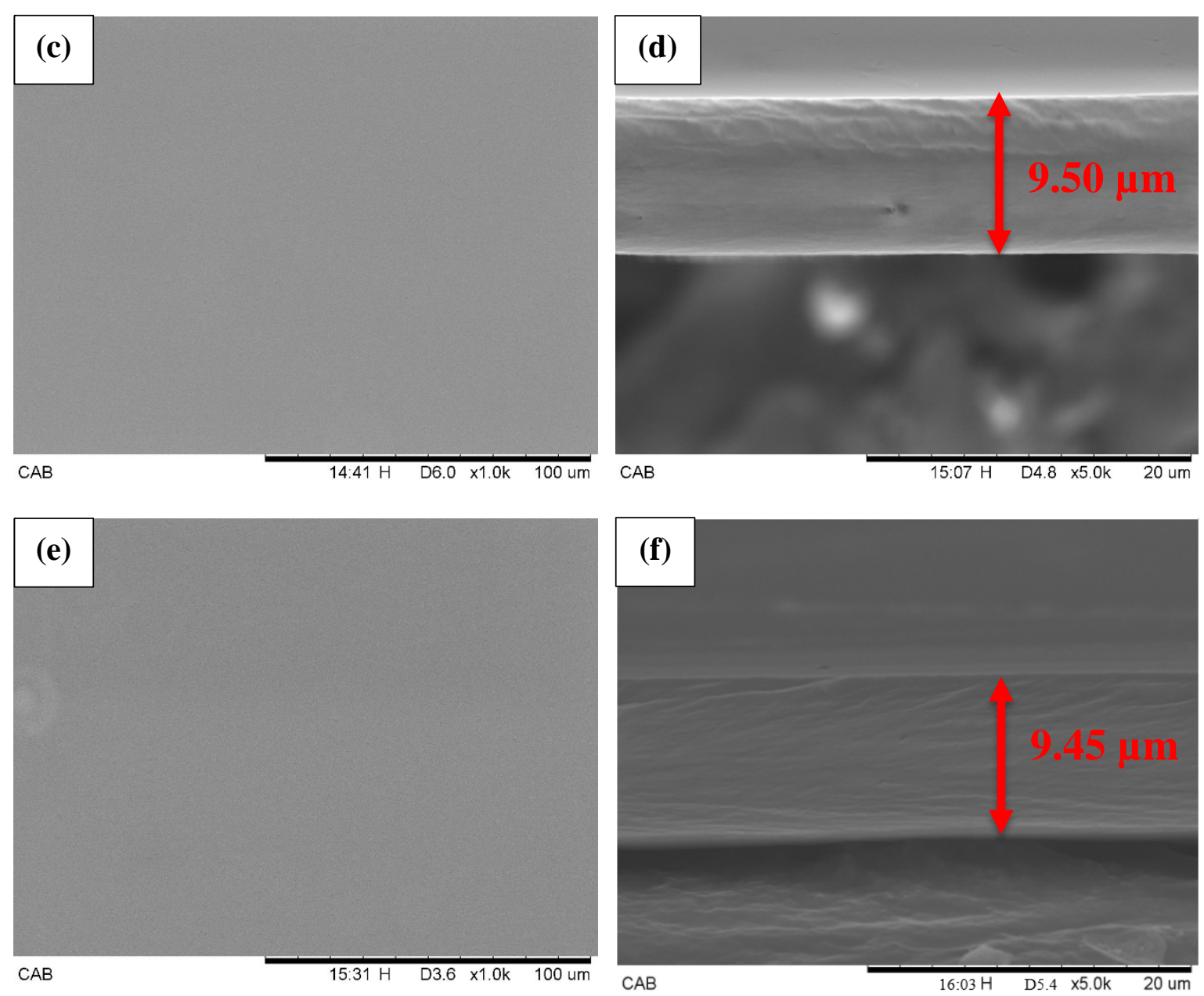

Fig 9. Surface and cross-sectional SEM of CAB membrane dried with 30 minutes of isopropyl alcohol first then followed by; (a-b) 15 minutes (CAB-15H), (c-d) 30 minutes (CAB$30 \mathrm{H}$ ), and (e-f) 60 minutes (CAB-60H) of solvent exchange time using n-hexane, at casting thickness of $250 \mu \mathrm{m}$ and 5 minutes solvent evaporation time

According to the $\mathrm{CO}_{2}$ permeance results displayed in Fig. 10, there was clear indication that CAB- $60 \mathrm{H}$ showed the highest $\mathrm{CO}_{2}$ permeance rate followed by $\mathrm{CAB}-30 \mathrm{H}$ and subsequently, by CAB15H. As seen in Fig. 10, the $\mathrm{CO}_{2}$ permeance increased significantly from $21.55 \pm 0.03 \mathrm{GPU}$ to 227.95 $\pm 0.39 \mathrm{GPU}$ when the solvent exchange time increased from 15 minutes (CAB-15H) to 30 minutes (CAB-30H). This was because when the exchange time was increased, sufficient time was provided for the exchange of the isopropyl alcohol content with n-hexane and therefore, generating a relatively thinner and compact cross-sectional membrane, which favoured $\mathrm{CO}_{2}$ permeation through the membrane (Jawad et al., 2015b). In addition, the $\mathrm{CO}_{2}$ permeance increased further when the solvent exchange duration was increased from 30 minutes to 60 minutes, as observed from CAB-30H (227.95 
$\pm 0.39 \mathrm{GPU})$ to $\mathrm{CAB}-60 \mathrm{H}(262.29 \pm 0.16 \mathrm{GPU})$. The increase in the $\mathrm{CO}_{2}$ permeance could be related to the increase in the number of the remaining polar n-hexane molecules within the membrane structure, resulting in a more active interaction with the $\mathrm{CO}_{2}$ molecules and hence, higher $\mathrm{CO}_{2}$ permeance yield (Jawad et al., 2015b).

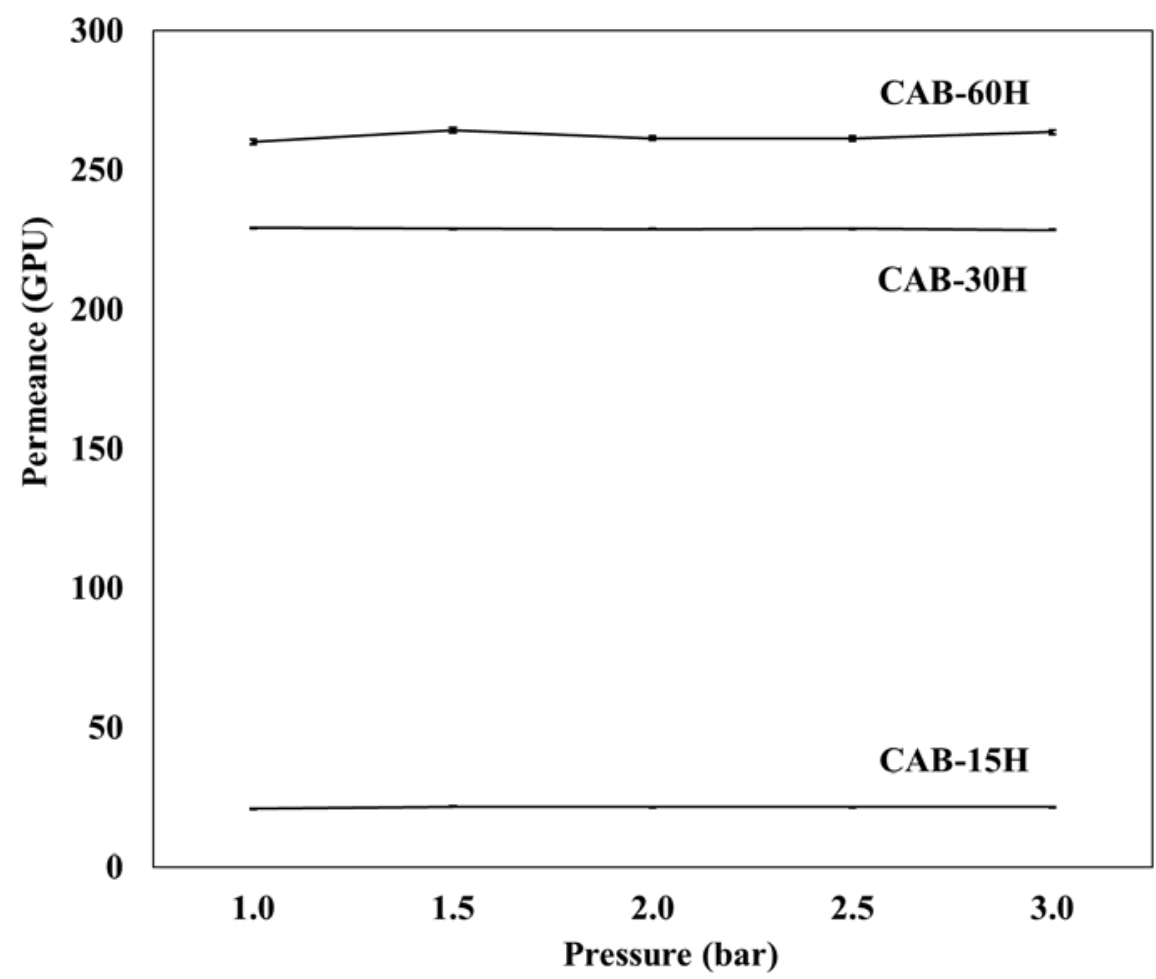

Fig 10. $\mathrm{CO}_{2}$ permeance for membrane dried with 15 minutes (CAB-15H), 30 minutes (CAB$30 \mathrm{H}$ ), and 60 minutes (CAB-60H) of $n$-hexane, at casting thickness of $250 \mu \mathrm{m}$ and 5 minutes solvent evaporation time

Meanwhile, Fig. 11 illustrated a drastic increase of $\mathrm{N}_{2}$ permeance from $10.03 \pm 0.02$ GPU to 37.28

$272 \pm 0.54 \mathrm{GPU}$ when the solvent exchange time of n-hexane was increased from 15 minutes (CAB-15H)

273 to 30 minutes (CAB-30H). The reason for this increment was mainly due to the thin dense membrane

274 structure of $\mathrm{CAB}-30 \mathrm{H}(9.50 \pm 0.10 \mu \mathrm{m})$, which allowed the feed of $\mathrm{N}_{2}$ gas to pass through a least

275 resistance pathway. However, the high $\mathrm{N}_{2}$ permeance for CAB-60H (70.49 $\left.\pm 0.33 \mathrm{GPU}\right)$ was due to

276 stress of surface tension caused by high capillary forces because of the evaporation of residual n-hexane

277 within the membrane, which led to the collapse in the structure (Matsuyama et al., 2002). 


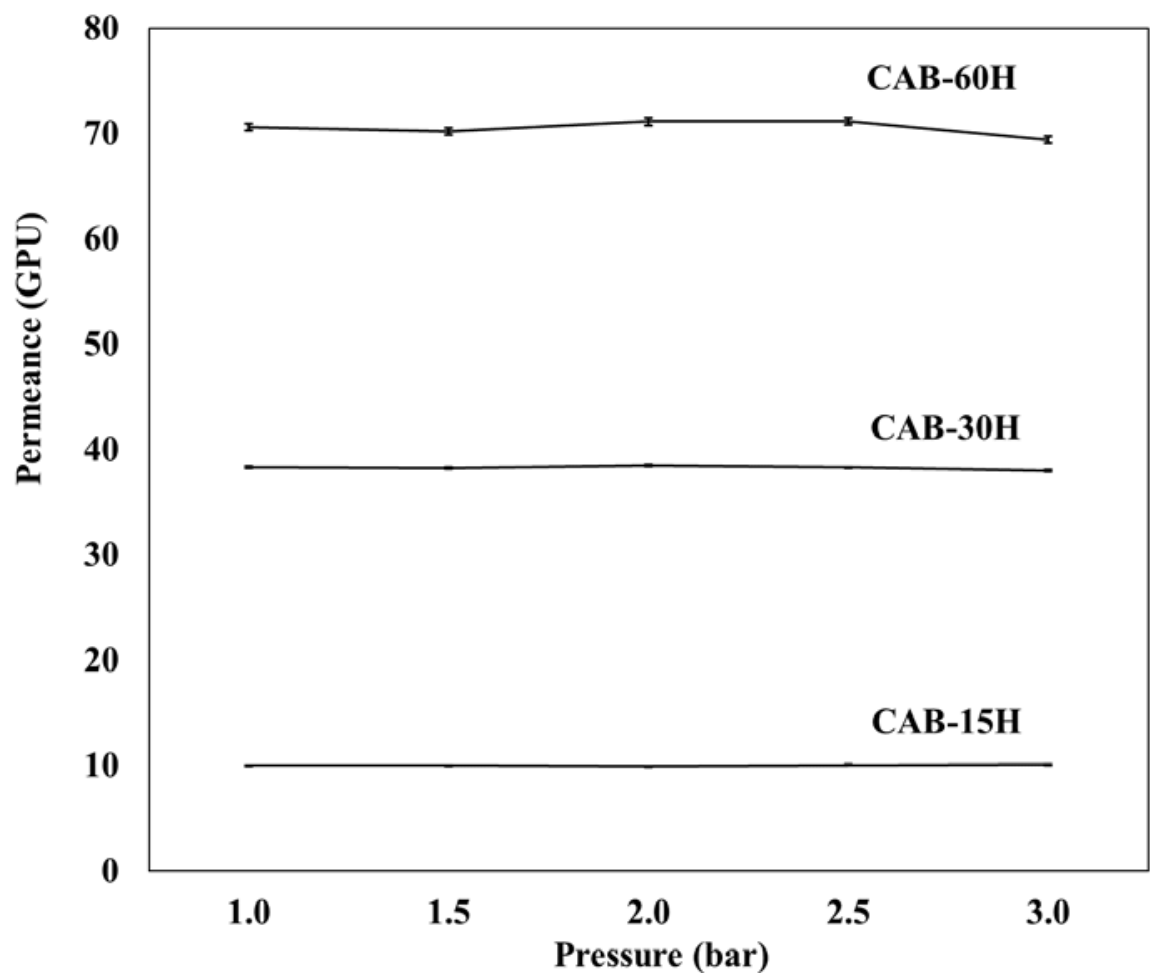

Fig 11. $\mathrm{N}_{2}$ permeance for membrane dried with 15 minutes $(\mathrm{CAB}-15 \mathrm{H}), 30$ minutes $(\mathrm{CAB}-30 \mathrm{H})$, and 60 minutes $(\mathrm{CAB}-60 \mathrm{H})$ of $\mathrm{n}$-hexane, at casting thickness of $250 \boldsymbol{\mu m}$ and 5 minutes solvent evaporation time

As seen in Fig. 12, the CAB-30H membrane showed the highest gas selectivity, which was achieved at $6.12 \pm 0.09$. This result further proved that to have a high gas separation performance a smooth surface with regular thin dense membrane morphology was preferable (Figs. 9c and d) (Huang and Feng, 1995, Jansen et al., 2005, Matsuyama et al., 2002, Lui et al., 1988). On the other hand, CAB$15 \mathrm{H}$ showed a lower separation performance of $2.15 \pm 0.17$. This was due to the collapse in the membrane structure caused by the short solvent immersion time, thereby generating an uneven porous surface and thick dense membrane structure, as presented in Figs. 9a and $\mathbf{b}$. However, CAB-60H exhibited a smooth surface and thinner dense membrane morphology $(9.45 \pm 0.06 \mu \mathrm{m})$, as depicted in Figs. 9e and $\mathbf{f}$. In addition, the low selectivity performance for CAB-60H (3.72 \pm 0.03$)$ was as a result of the excessive exchange time with n-hexane, which deformed the functionality of the membrane and therefore, generated moderate selectivity performance (Budd et al., 2005). 


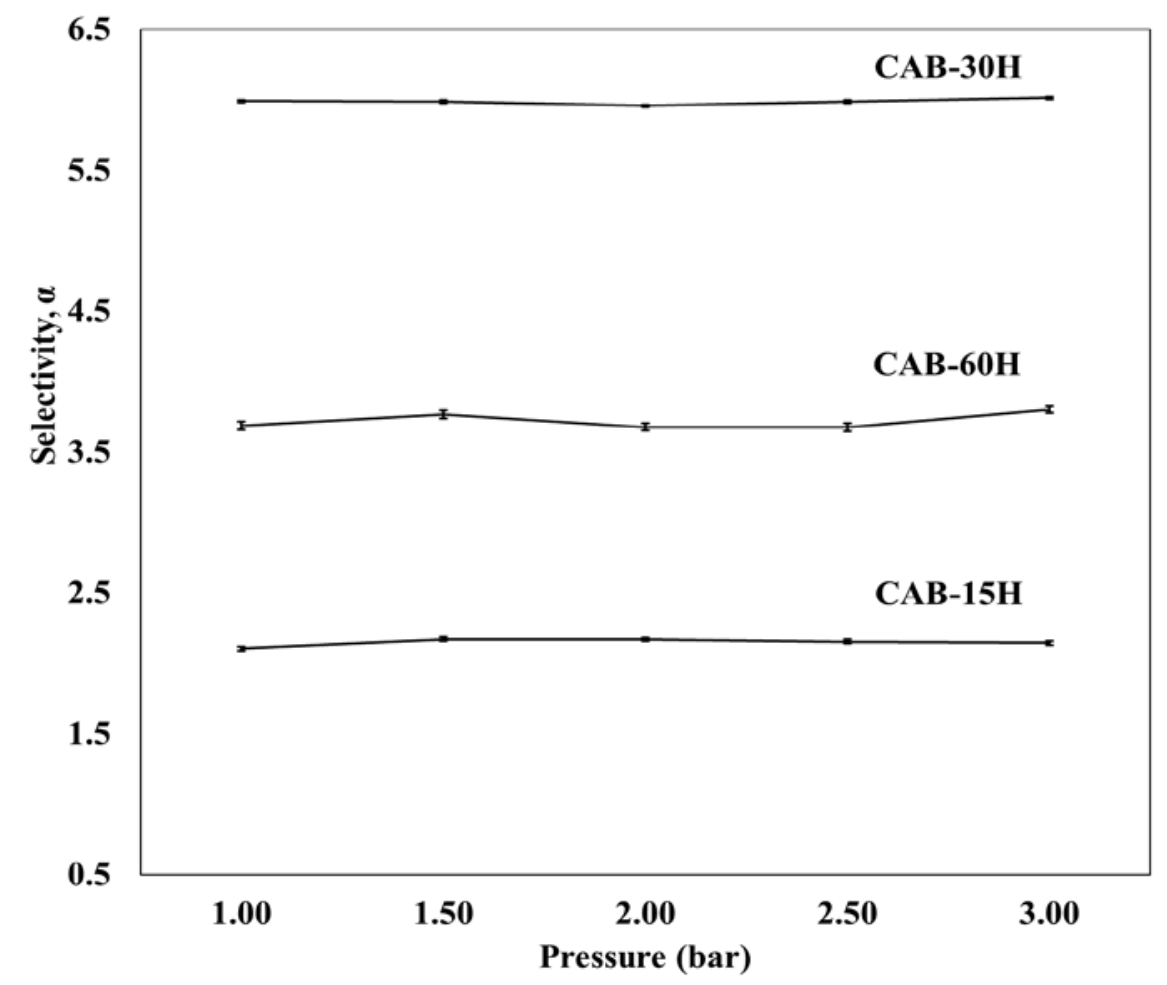

Fig 12. Ideal selectivity of $\mathrm{CO}_{2} / \mathrm{N}_{2}$ for $\mathrm{CAB}$ membrane dried with 30 minutes of isopropyl alcohol first then followed by; 15 minutes (CAB-15H), 30 minutes (CAB-30H), and 60 minutes $(\mathrm{CAB}-60 \mathrm{H})$ of solvent exchange with $\mathrm{n}$-hexane, at casting thickness of $250 \mathrm{\mu m}$ and 5 minutes solvent evaporation time

\subsection{The Effect of CAB polymer at different molecular weight $\left(M_{n}\right)$}

According to Coltelli et al. (2008), the acetyl group has been deduced to have prominent effect on the

membrane gas separation performance, as excessive acetyl composition in the membrane could promote plasticisation within the membrane (Coltelli et al., 2008, Ismail and Lorna, 2002). Thus, different CAB molecular weights with different acetyl, butyryl, and hydroxyl groups were investigated, as demonstrated in Fig. 13.

As depicted in Figs. 13a and c, a porous structure was observed for both CAB-12000 $\left(M_{n}=12000\right)$ and CAB-65000 $\left(M_{n}=65000\right)$, while CAB-70000 $\left(M_{n}=70000\right)$ showed a smooth surface (Fig. 13e). The reason the membrane surface changed from porous to smooth was due to the high molecular weights of $\mathrm{CAB}$, which caused the increase in the number of entanglements between the macromolecular chains in the solution (Jansen et al., 2006). Therefore, the high molecular weights of CAB favoured the gelation of the polymer rich phase after the phase-inversion occurred and hence, suppressed the formation of the porous structure during the early stages (Jansen et al., 2005). 
$31210.96 \pm 0.10,16.05 \pm 0.17$, and $9.50 \pm 0.10 \mu \mathrm{m}$, respectively. The increment in the CAB molecular

313 weights further influenced the membrane thickness through the rheological properties of the casting

314 solution (Jansen et al., 2005). This was due to the high molecular weights of the CAB polymer being

315 utilised for membrane fabrication, which gave the rapid gelation (Jansen et al., 2005). After the rapid

316 gelation, the porous structure was greatly suppressed and further evaporation of solvent and non-solvent

317 from the polymer matrix resulted in gradual shrinkage of the structure (Jansen et al., 2005). Therefore,

318 the thickness of CAB-70000 $(9.50 \pm 0.10 \mu \mathrm{m})$ was thinner than CAB-12000 $(10.96 \pm 0.10 \mu \mathrm{m})$ and

319 CAB-65000 $(16.05 \pm 0.17 \mu \mathrm{m})$.

320
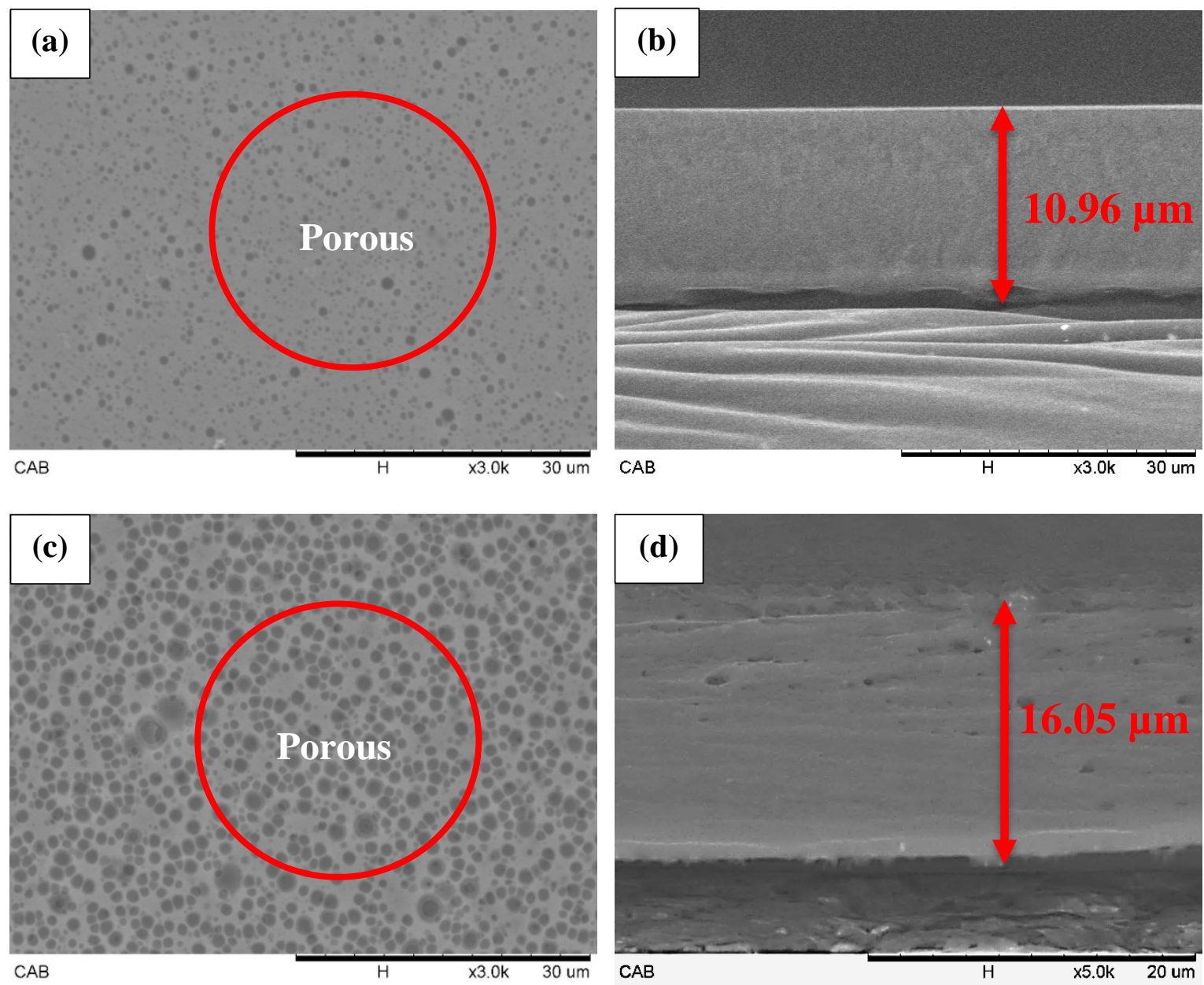

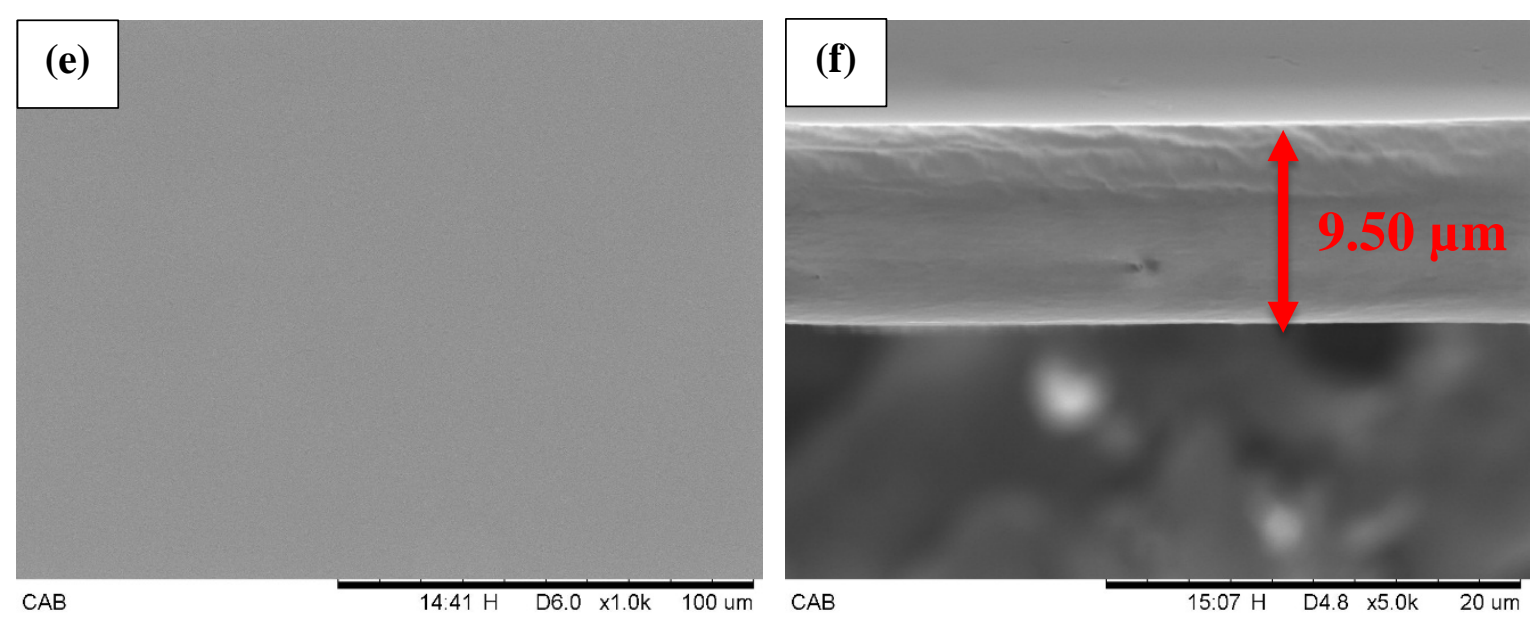

Fig 13. Surface and cross-sectional SEM of CAB membranes prepared with polymer concentration of $4 \mathrm{wt} \%$ and molecular weights $\left(M_{\mathrm{n}}\right)$ of $(\mathrm{a}-\mathrm{b}) 12000$ (CAB-12000), (c-d) 65000 (CAB-65000), and (e-f) 70000 (CAB-70000), at casting thickness of $250 \mu \mathrm{m}$ and 5 minutes solvent evaporation time

The performance of $\mathrm{CO}_{2}$ permeance achieved for the different molecular weights $\left(M_{\mathrm{n}}\right)$ of CAB12000, CAB-65000, and CAB-70000 were $101.42 \pm 0.97,74.37 \pm 1.25$, and $227.95 \pm 0.39$ GPU, respectively, as shown in Fig. 14. The decrease in the $\mathrm{CO}_{2}$ permeance rates observed from CAB-12000 (28-31 wt\%) to CAB-65000 (16-19 wt\%) was due to the thick dense membrane morphology as presented in Fig. 13d (16.05 $\pm 0.17 \mu \mathrm{m})$, which can hindrance the $\mathrm{CO}_{2}$ permeance (Jawad et al., 2015a). Meanwhile, CAB-12000, which exhibited greater membrane thickness of $10.96 \pm 0.10 \mu \mathrm{m}$, contradicted the results with higher $\mathrm{CO}_{2}$ permeance, as illustrated in Fig. 14. The possible explanation for the increase in $\mathrm{CO}_{2}$ permeance was caused by the acetyl groups rigidity and steric effects (Wan et al., 2003). Therefore, this allowed the higher intrinsic solubility of $\mathrm{CO}_{2}$ due to the greater number of acetyl-acetyl interactions that existed (Koros et al., 1988b, Scholes et al., 2012). In addition, increasing the CAB molecular weight from 65000 to 70000 had increased the permeance rate drastically from $74.37 \pm 1.25$ GPU to $227.95 \pm 0.39$ GPU. Even though, CAB-70000 (12-15 wt\%) has the lowest acetyl-acetyl interactions due to low acetyl group composition compared to other CAB polymers. The significant increase in the $\mathrm{CO}_{2}$ permeance was due to the thin dense membrane exhibited for CAB-70000, as thin dense membrane usually impose less flux resistance for the membrane (Pandey and Chauhan, 2001). Therefore, the permeance of $\mathrm{CO}_{2}$ was highest among all as the membrane thickness was the thinnest. 


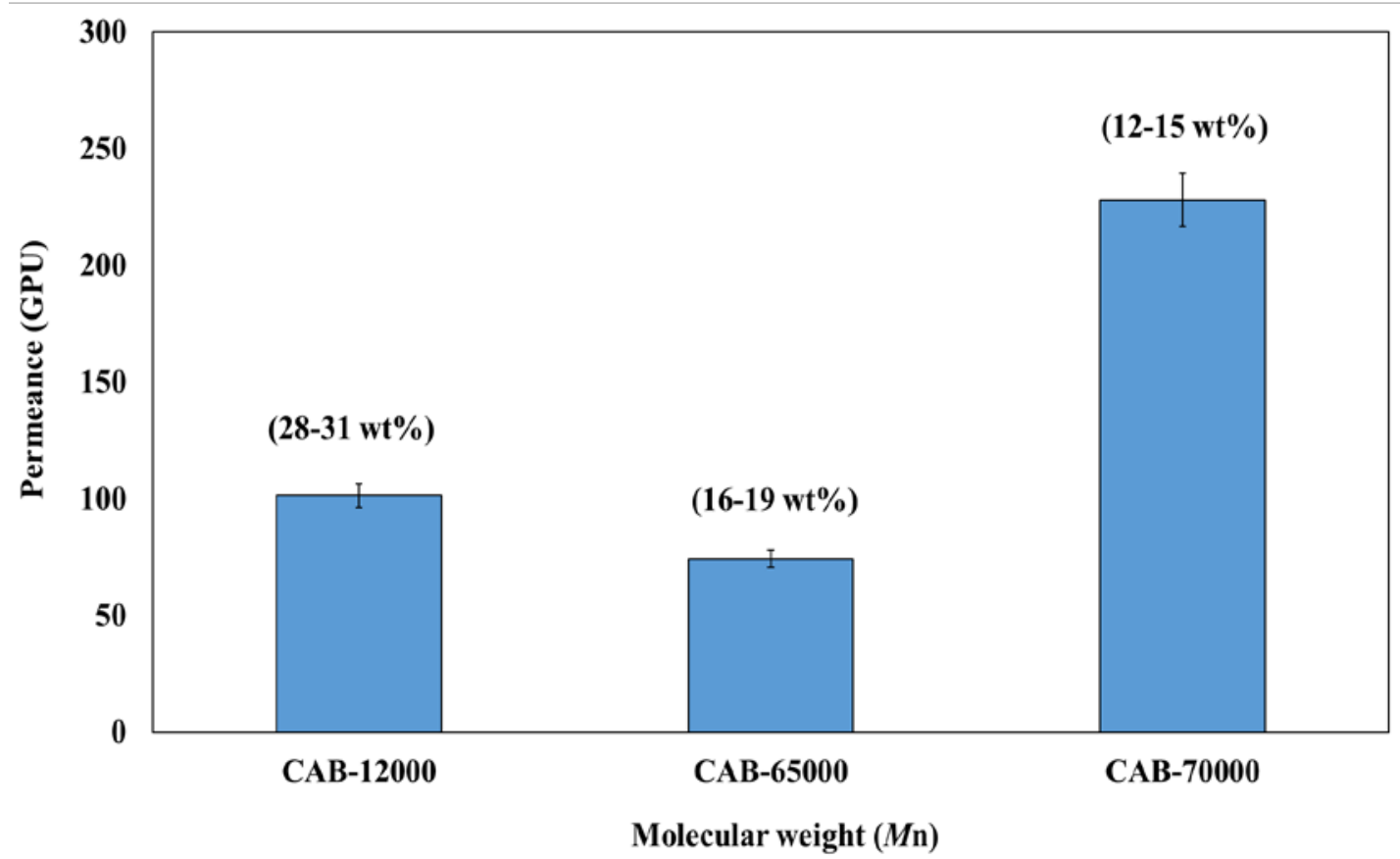

Fig 14. $\mathrm{CO}_{2}$ permeance results for $\mathrm{CAB}$ membranes fabricated at different molecular weights comprising CAB-12000, CAB-65000, and CAB-70000 acetyl content of 28-31 wt\%, 16$19 \mathrm{wt} \%$, and $12-15 \mathrm{wt} \%$, respectively

As portrayed in Fig. 15, the $\mathrm{N}_{2}$ permeance rate achieved for CAB-12000, CAB-65000, and CAB-

34370000 were $95.26 \pm 1.06,48.94 \pm 0.89$, and $37.28 \pm 0.54$ GPU, respectively. The reduction in $\mathrm{N}_{2}$

344 permeance was due to the high presence of the hydroxyl group (1.2-2.2 wt\%) content within the CAB-

34570000 polymer. The reaction between the hydroxyl and carbonyl groups of the CAB polymer caused

346 the formation of hydrogen bonds, which could delay the de-mixing between the coagulant and the non-

347 solvent. This resulted in the smooth homogeneous formation of the membrane surface, which could

348 influence the $\mathrm{N}_{2}$ permeance rate (Childress and Elimelech, 1996). Thus, it may be deduced that with the

349 increment of the hydroxyl group within the membrane composition, the formation of a homogeneous

350 surface morphology was favoured. Further, the hydroxyl group can increase the preferential restrictions

351 on membrane pore formation, whereby the permeance and diffusion coefficient can be suppressed,

352 hence, enhancing the selectivity performance of the membrane (Yave et al., 2009). 


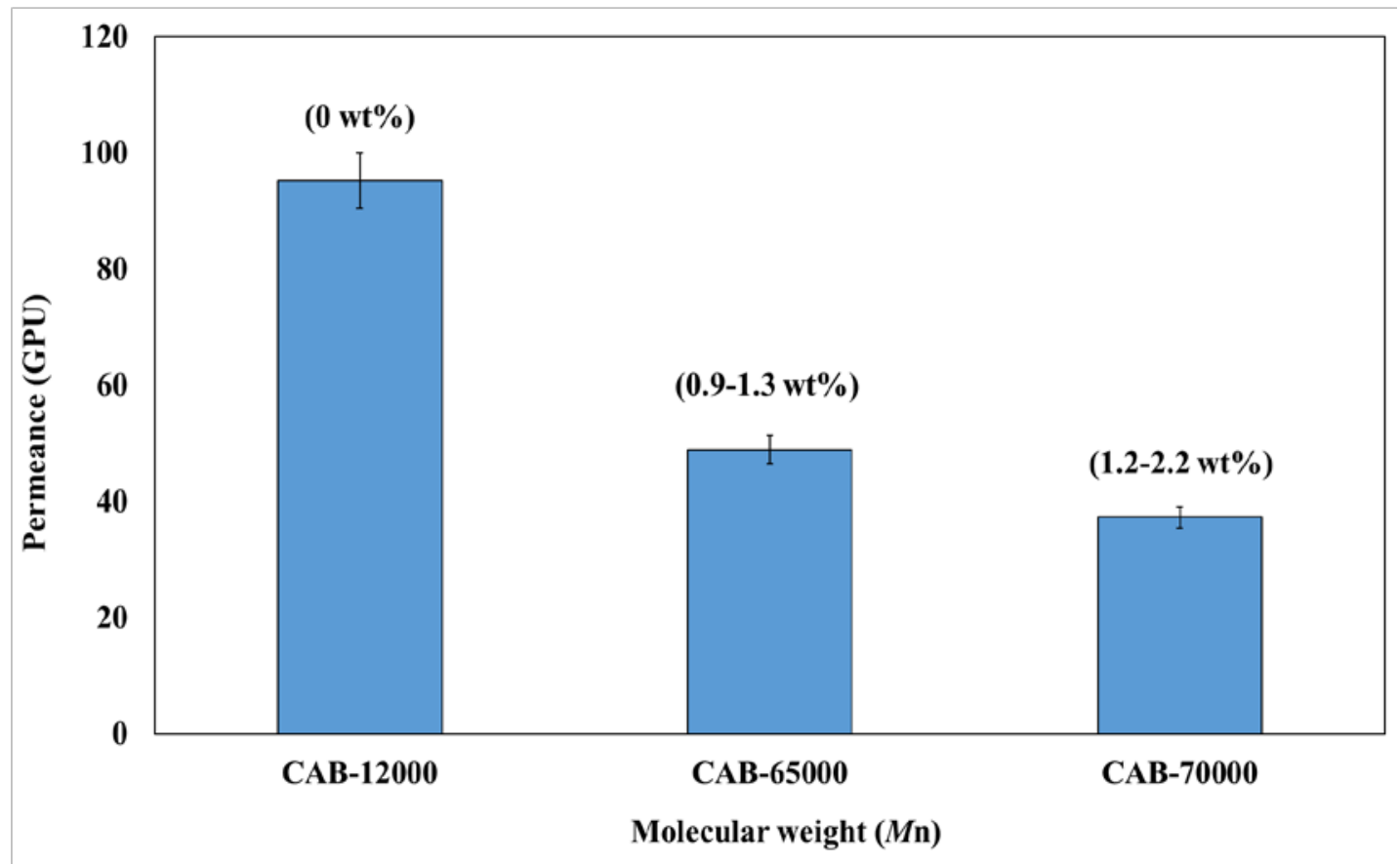

Fig 15. $\mathrm{N}_{2}$ permeance results for $\mathrm{CAB}$ membranes synthesised at different molecular weights comprising CAB-12000, CAB-65000, and CAB-70000 hydroxyl content of 0 wt \%, 0.9$1.3 \mathrm{wt} \%$, and 1.2-2.2 wt \%, respectively

Fig. 16 reveals the selectivity results for the different CAB molecular weights of 12000 (CAB12000), 65000 (CAB-65000), and 70000 (CAB-70000), respectively. From the selectivity results

356 depicted in Fig. 16, CAB-70000 achieved the average highest selectivity of $6.12 \pm 0.09$, followed by 357 CAB-65000 with a moderate selectivity of $1.52 \pm 0.04$, and CAB-12000 with the lowest selectivity of $3581.06 \pm 0.01$. The high selectivity performance of CAB-70000 was due to the high presence of the butyryl 359 group content (35-39 wt\%), which promoted the $\mathrm{CO}_{2}$ diffusion better due to the increase of the non360 polar butyryl chain within the structure of the membrane, thus, making the membrane more hydrophobic 361 in nature (Wan et al., 2004, Ong et al., 2012). 


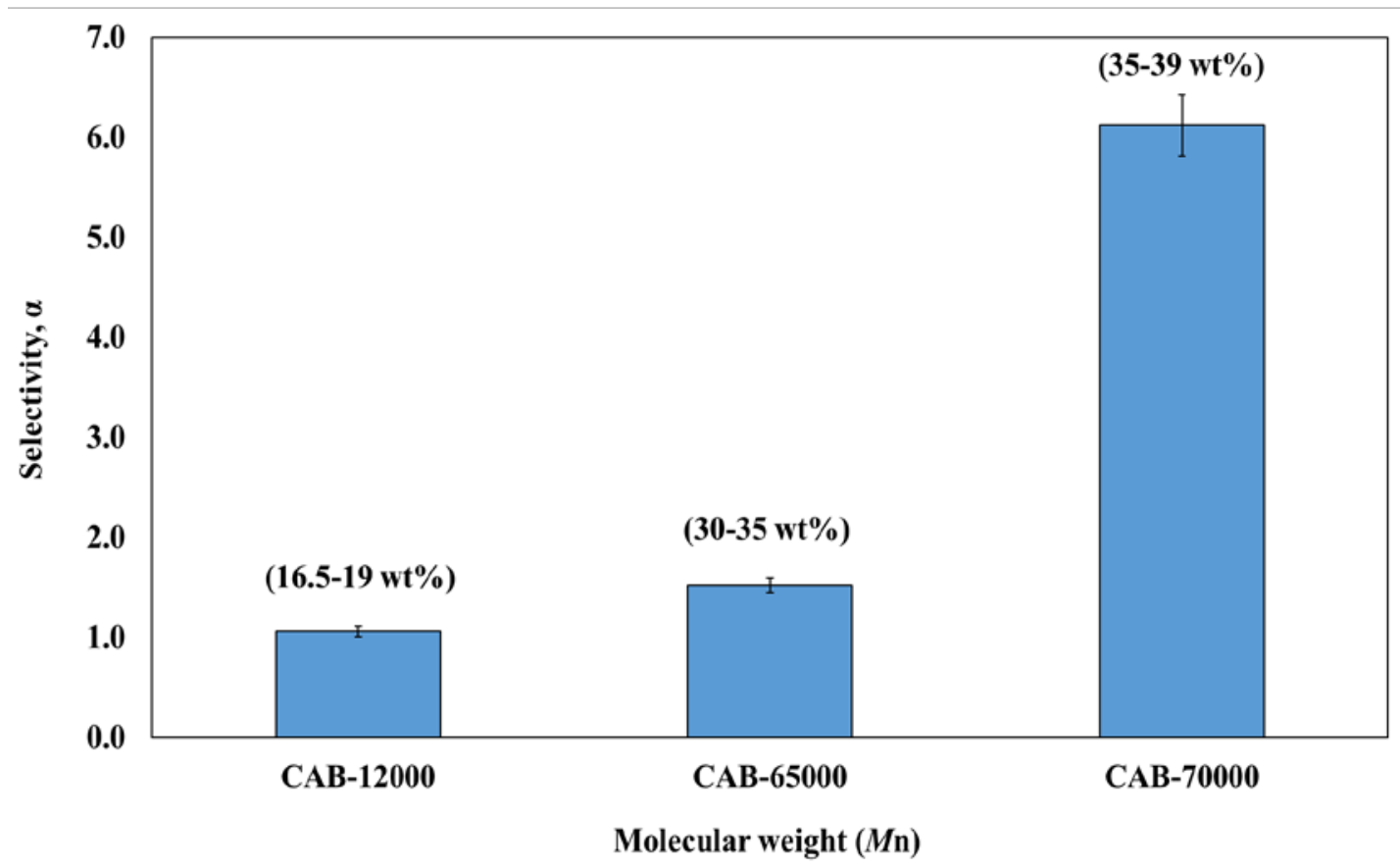

Fig 16. $\mathrm{CO}_{2} / \mathrm{N}_{2}$ selectivity results for $\mathrm{CAB}$ membranes at different molecular weights comprising CAB-12000, CAB-65000, and CAB-70000 butyryl content of 16.5-19 wt\%, $30-35 \mathrm{wt} \%$, and $35-39 \mathrm{wt} \%$, respectively

\section{3.4.1 X-ray Photoelectron Spectroscopy (XPS) Analysis}

364 The XPS characterisation was adopted in this study to analyse the quantitative element composition of 365 the $\mathrm{CAB}$ membrane fabricated. The quantitative element composition of the membrane surface can be determined from the spectrum obtained. Consequently, CAB-12000, CAB-65000, and CAB-70000 were analysed through XPS analysis. The surface chemical quantitative compositions are depicted in Table 1 and Fig. 17, respectively.

Observing the results tabulated in Table 1, both the atomic and mass concentration of the oxygen (O) atom decreased with the increase in the $\mathrm{CAB}$ membrane molecular weights. The decreasing trend 371 of atomic concentration from $34.02>30.88>27.30 \%$ and mass concentration from $40.72>37.31>33.35 \%$

372 of the $\mathrm{O}$ atom was due to the decrease of the acetyl group derived from each $\mathrm{CAB}$ polymer 373 (Suttiwijitpukdee et al., 2011). As indicated clearly in Fig. 14, the acetyl group affected the permeance of $\mathrm{CO}_{2}$ within the membrane. Hence, this further proved that increasing the acetyl group or $\mathrm{O}$ atom presence within the membrane subsequently, decreased the permeance of $\mathrm{CO}_{2}$. The increase in the $\mathrm{O}$

376 element was mainly funded by the breaking of the carbonyl $(\mathrm{C}=\mathrm{O})$ group and prompted the formation 
of a new carboxyl group (-COOH) (Liu et al., 2014). The increase in carboxyl group made the membrane

378 more hydrophilic, resulting in decline of the $\mathrm{CO}_{2}$ permeance flux (Xia and Ni, 2015, Xu et al., 2014).

Table 1. Element composition of the CAB membrane synthesized at different molecular weight

\begin{tabular}{lcccccc}
\hline & \multicolumn{2}{c}{ CAB-12000 } & \multicolumn{2}{c}{ CAB-65000 } & \multicolumn{2}{c}{ CAB-70000 } \\
Peak & Atomic & Mass & Atomic & Mass & Atomic & Mass \\
& Conc \% & Conc \% & Conc \% & Conc \% & Conc \% & Conc \% \\
\hline O 1s & 34.02 & 40.72 & 30.88 & 37.31 & 27.30 & 33.35 \\
C 1s & 65.98 & 59.28 & 69.12 & 62.69 & 72.70 & 66.65 \\
\hline
\end{tabular}

On the other hand, when observing the carbon (C) element present within CAB-12000, CAB65000, and CAB-70000, the C atoms increased with increase in the polymer molecular weights. The atomic concentration increased from $65.98>69.12>72.70$ and the mass concentration increased from 59.28>62.69>66.65 for CAB-12000, CAB-65000, and CAB-70000, respectively. The increase in the C element within the membrane was because of the increase in the butyryl group within the CAB polymer. As indicated in Fig. 16, the butyryl group played a crucial role in manipulating the selectivity performance of the membrane, because it can increase the $\mathrm{CO}_{2}$ diffusion due to the increase of the nonpolar butyryl chain within the structure of the membrane (Wan et al., 2004). As a result the membrane became more hydrophobic in nature, and hence, promoted better $\mathrm{CO}_{2}$ permeance flux (Ong et al., 2012). 

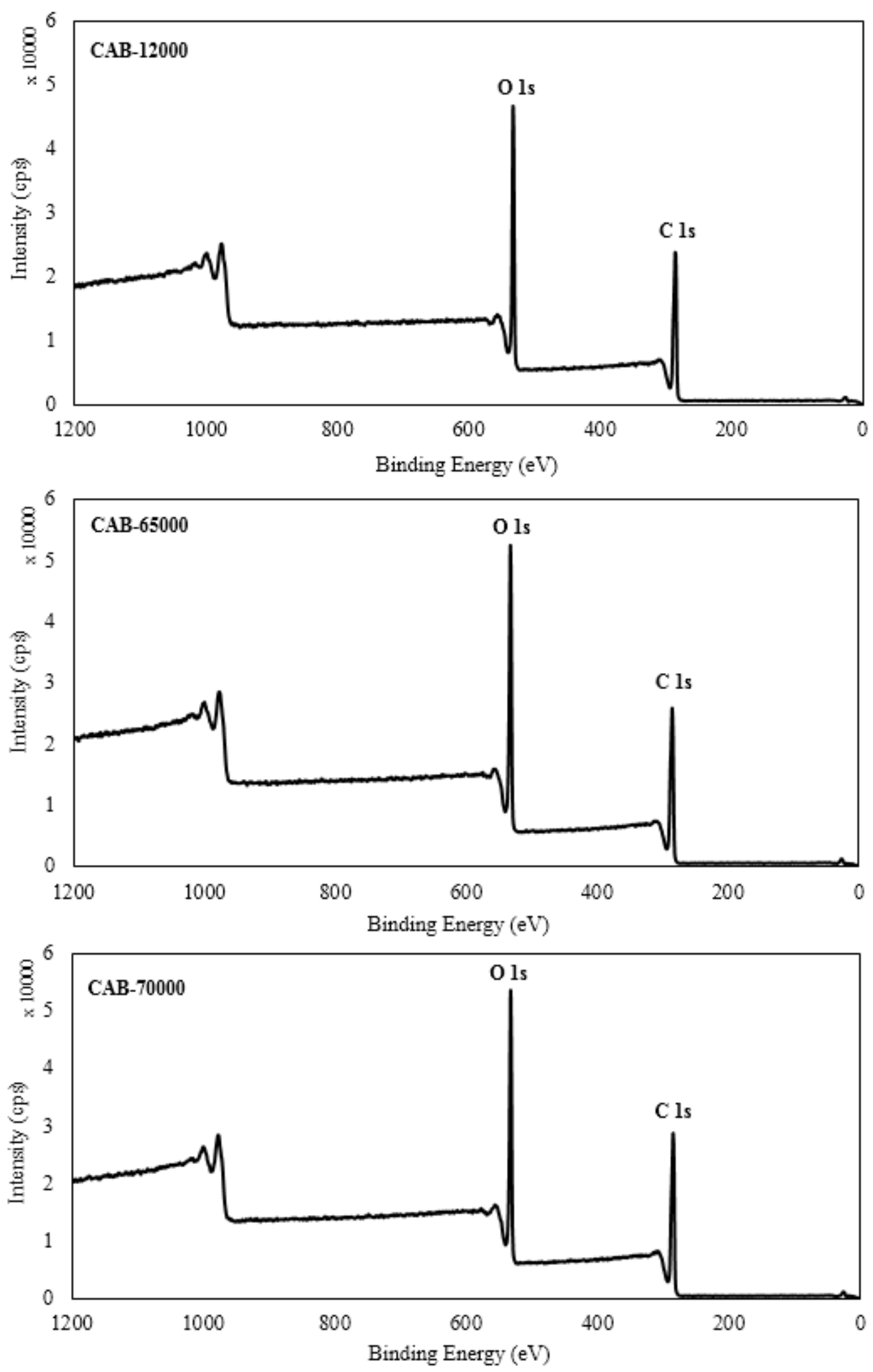

Fig 17. Element composition of XPS spectrum of CAB-12000, CAB-65000, and CAB-70000 
391 other research works, as shown in Table 2. In this study, the best membrane performance achieved for 392 both $\mathrm{CO}_{2}$ permeance and selectivity was $227.95 \pm 0.39 \mathrm{GPU}$ and $6.12 \pm 0.09$, respectively for CAB393 70000. This was a result of the dynamic contents of acetyl, butyryl, and hydroxyl composition present 394 in CAB polymer. The acetyl and butyryl contributed significantly towards the permeance of $\mathrm{CO}_{2} / \mathrm{N}_{2}$ by 395 enhancing the solubility of $\mathrm{CO}_{2}$ within the membrane structure. As compared to other research works, 396 the permeance results achieved in the present work showed higher $\mathrm{CO}_{2} / \mathrm{N}_{2}$ permeance with acceptable 397 selectivity result. The selectivity performance achieved for this study shows the typical trade-off 398 relationship of polymer membrane due to the high permeance results and low selectivity of the CAB 399 polymer. Nevertheless, the low selectivity of the CAB polymer can eventually be overcome by 400 incorporating the polymer matrix with inorganic filler to produce the hybrid system of mixed matrix 401 membranes (MMMs) (Aroon et al., 2013, Chung et al., 2007, Ismail et al., 2009, Goh et al., 2011).

Table 2. List of $\mathrm{CO}_{2} / \mathrm{N}_{2}$ permeation results achieved from current study with previous work

\begin{tabular}{|c|c|c|c|c|c|}
\hline Polymer & $\mathbf{P}\left(\mathrm{CO}_{2}\right)$ & $\mathbf{P}\left(\mathbf{N}_{2}\right)$ & & Conditions & References \\
\hline CAB & $\begin{array}{c}164.84 \pm \\
0.73^{\mathrm{a}}\end{array}$ & $\begin{array}{c}26.36 \pm \\
0.05^{\mathrm{a}}\end{array}$ & $\begin{array}{c}6.06 \pm \\
0.23\end{array}$ & $\begin{array}{l}1-3 \times 10^{5} \mathrm{~Pa}, \\
\text { casting thickness } \\
\text { of } 250 \mu \mathrm{m}\end{array}$ & Present work \\
\hline SPEEK & 5.01 & 1.94 & 5.58 & $\begin{array}{l}1-1.5 \times 10^{5} \mathrm{~Pa}, 25 \\
{ }^{\circ} \mathrm{C} \text {, casting } \\
\text { thickness of } 60- \\
80 \mu \mathrm{m}\end{array}$ & (Xin et al., 2015) \\
\hline ВРPO & $76.78^{b}$ & N/A & 30 & $\begin{array}{l}0.7 \times 10^{5} \mathrm{~Pa}, \\
\text { casting thickness } \\
\text { of } 50-90 \mu \mathrm{m}\end{array}$ & (Cong et al., 2007) \\
\hline PES & $10.98^{\mathrm{a}}$ & $0.80^{\mathrm{a}}$ & 13.73 & $\begin{array}{l}3-4 \times 10^{5} \mathrm{~Pa}, \\
\text { casting thickness } \\
\text { of } 150 \mu \mathrm{m}\end{array}$ & (Ismail et al., 2011) \\
\hline $\begin{array}{l}\text { 6FDA- } \\
\text { durene }\end{array}$ & $30.3^{b}$ & $2.87^{b}$ & 10.56 & $\begin{array}{l}35^{\circ} \mathrm{C}, 10 \mathrm{~atm}, \\
\text { casting thickness } \\
\text { of } 40 \mu \mathrm{m}\end{array}$ & (Liu et al., 2001) \\
\hline
\end{tabular}

406

407

\subsection{Conclusion}

408 The optimisation of membrane morphology conducted with respect to the different parameters was 409 found to be successful for the preparation of the highly selective CAB gas separation membrane. The 
membrane formation and morphology were closely related to the rheological behaviour of the casting

411 solution. The results have shown that membrane casting thickness, solvent exchange duration for both

412 isopropyl alcohol and n-hexane, and the molecular weights of the CAB polymer had a significant role

413 in manipulating the $\mathrm{CO}_{2} / \mathrm{N}_{2}$ gas separation performance as well as the morphology of the membranes.

414 Under optimised conditions, the best membrane was found to be the CAB-70000, which was fabricated

415

416

417

418 with 4 wt\% polymer concentration, $250 \mu \mathrm{m}$ casting thickness, 5 minutes solvent evaporation time, 30 minutes solvent exchange with isopropyl alcohol followed by another 30 minutes of solvent exchange with n-hexane. Moreover, the CAB-70000 had the best gas separation performance with an average selectivity of $6.12 \pm 0.09$ and permeance up to $227.95 \pm 0.39 \mathrm{GPU}$ for $\mathrm{CO}_{2}$ and $37.28 \pm 0.54 \mathrm{GPU}$ for $\mathrm{N}_{2}$, respectively. The superior $\mathrm{CO}_{2} / \mathrm{N}_{2}$ separation performance of the membrane was mainly contributed by the quality formation of the smooth surface, with thin dense and defect-free membrane structure. Further, it has been suggested that to improve the performance of the CAB membrane, inorganic nanoparticle fillers such as carbon nanotubes (CNTs) be incorporated to produce mixed matrix membrane (MMM).

\section{Acknowledgement}

The authors would like to extend their appreciation to the Ministry of Higher Education Malaysia (MOHE) for providing Fundamental Research Grant Scheme (FRGS) (MOHE Ref. No: FRGS/1/2015/TK02/CURTIN/03/1) and Cost Centre: 001048. Further, the authors would also like to thank LRGS USM (Account No: 304/PJKIMIA/6050296/U124), and Curtin Cost Centre: 001047.

Keywords: Membrane gas separation; Cellulose acetate butyrate; casting thickness; solvent exchange time; isopropyl alcohol; n-hexane; molecular weight; functional groups; Scanning Electron Micrograph; X- ray Photoelectron Spectroscopy 


\section{References}

Ahmad, A., Ideris, N., Ooi, B., Low, S. and Ismail, A. 2013. Synthesis of polyvinylidene fluoride (PVDF) membranes for protein binding: Effect of casting thickness. Journal of Applied Polymer Science, 128, 3438-3445.

Ahmad, A., Jawad, Z., Low, S. and Zein, S. 2014. A cellulose acetate/multi-walled carbon nanotube mixed matrix membrane for $\mathrm{CO}_{2} / \mathrm{N}_{2}$ separation. Journal of Membrane Science, 451, 55-66.

Aroon, M. A., Ismail, A. F. and Matsuura, T. 2013. Beta-cyclodextrin functionalized MWCNT: A potential nano-membrane material for mixed matrix gas separation membranes development. Separation and Purification Technology, 115, 39-50.

Barnes, R. J., Bandi, R. R., Chua, F., Low, J. H., Aung, T., Barraud, N., Fane, A. G., Kjelleberg, S. and Rice, S. A. 2014. The roles of Pseudomonas aeruginosa extracellular polysaccharides in biofouling of reverse osmosis membranes and nitric oxide induced dispersal. Journal of Membrane Science, 466, 161-172.

Basu, S., Khan, A. L., Cano-Odena, A., Liu, C. and Vankelecom, I. F. J. 2010. Membrane-based technologies for biogas separations. Chemical Society Reviews, 39, 750-768.

Budd, P. M., Msayib, K. J., Tattershall, C. E., Ghanem, B. S., Reynolds, K. J., Mckeown, N. B. and Fritsch, D. 2005. Gas separation membranes from polymers of intrinsic microporosity. Journal of Membrane Science, 251, 263-269.

Carapellucci, R. and Milazzo, A. 2003. Membrane systems for $\mathrm{CO}_{2}$ capture and their integration with gas turbine plants. Proceedings of the Institution of Mechanical Engineers, Part A: Journal of Power and Energy, 217, 505-517.

Childress, A. E. and Elimelech, M. 1996. Effect of solution chemistry on the surface charge of polymeric reverse osmosis and nanofiltration membranes. Journal of membrane science, 119, 253-268.

Choi, J. H., Jegal, J. and Kim, W. N. 2006. Fabrication and characterization of multi-walled carbon nanotubes/polymer blend membranes. Journal of Membrane Science, 284, 406-415.

Chung, T. S., Jiang, L. Y., Li, Y. and Kulprathipanja, S. 2007. Mixed matrix membranes (MMMs) comprising organic polymers with dispersed inorganic fillers for gas separation. Progress in Polymer Science, 32, 483-507.

Chung, T. and Kafchinski, E. R. 1997. The effects of spinning conditions on asymmetric 6FDA/6FDAM polyimide hollow fibers for air separation. Journal of applied polymer science, 65, 1555-1569.

Coltelli, M. B., Maggiore, I. D., Bertoldo, M., Signori, F., Bronco, S. and Ciardelli, F. 2008. Poly (lactic acid) properties as a consequence of poly (butylene adipate-co-terephthalate) blending and acetyl tributyl citrate plasticization. Journal of Applied Polymer Science, 110, 1250-1262.

Cong, H., Zhang, J., Radosz, M. and Shen, Y. 2007. Carbon nanotube composite membranes of brominated poly (2, 6-diphenyl-1, 4-phenylene oxide) for gas separation. Journal of Membrane Science, 294, 178-185.

Conti, J., Holtberg, P., Diefenderfer, J., Larose, A., Turnure, J.T. and Westfall, L., 2016. International Energy Outlook 2016 With Projections to 2040 (No. DOE/EIA--0484 (2016)). USDOE Energy Information Administration (EIA), Washington, DC (United States). Office of Energy Analysis.

Egan, W. M. and Dufresne, R. E. 2008. Gelled adhesive remover composition and method of use. U.S. Patent 7,977,294.

Feng, Y., Zhang, J. M., Zhang, J. and Chang, J. 2015. Gas Separation Properties of Cellulose Acetate Butyrate/MWCNTs Mixed Matrix Membranes. ACTA POLYMERICA SINICA, 1396-1401.

Freeman, B. D. 1999. Basis of permeability/selectivity tradeoff relations in polymeric gas separation membranes. Macromolecules, 32, 375-380. 
Goh, P. S., Ismail, A. F., Sanip, S. M., Ng, B. C. and Aziz, M. 2011. Recent advances of inorganic fillers in mixed matrix membrane for gas separation. Separation and Purification Technology, 81, 243264.

Hansen, C. M. 2007. Hansen solubility parameters: a user's handbook, CRC press.

Huang, R. Y. and Feng, X. 1995. Studies on solvent evaporation and polymer precipitation pertinent to the formation of asymmetric polyetherimide membranes. Journal of applied polymer science, 57, 613-621.

Ismail, A. F., Goh, P. S., Sanip, S. M. and Aziz, M. 2009. Transport and separation properties of carbon nanotube-mixed matrix membrane. Separation and Purification Technology, 70, 12-26.

Ismail, A. F. and Lorna, W. 2002. Penetrant-induced plasticization phenomenon in glassy polymers for gas separation membrane. Separation and purification technology, 27, 173-194.

Ismail, A. F., Rahim, N., Mustafa, A., Matsuura, T., Ng, B. C., Abdullah, S. and Hashemifard, S. A. 2011. Gas separation performance of polyethersulfone/multi-walled carbon nanotubes mixed matrix membranes. Separation and purification technology, 80, 20-31.

Jansen, J. C., Buonomenna, M. G., Figoli, A. and Drioli, E. 2006. Asymmetric membranes of modified poly (ether ether ketone) with an ultra-thin skin for gas and vapour separations. Journal of membrane science, 272, 188-197.

Jansen, J. C., Macchione, M., Oliviero, C., Mendichi, R., Ranieri, G. A. and Drioli, E. 2005. Rheological evaluation of the influence of polymer concentration and molar mass distribution on the formation and performance of asymmetric gas separation membranes prepared by dry phase inversion. Polymer, 46, 11366-11379.

Jawad, Z., Ahmad, A., Low, S. and Zein, S. 2015a. Incorporation of inorganic carbon nanotubes fillers into the CA polymeric matrix for improvement in $\mathrm{CO}_{2} / \mathrm{N}_{2}$ separation. Current Nanoscience, 11 , 69-79.

Jawad, Z. A., Ahmad, A. L., Low, S. C., Chew, T. L. and Zein, S. H. S. 2015b. Influence of solvent exchange time on mixed matrix membrane separation performance for $\mathrm{CO}_{2} / \mathrm{N}_{2}$ and a kinetic sorption study. Journal of Membrane Science, 476, 590-601.

Kappel, C., Kemperman, A., Temmink, H., Zwijnenburg, A., Rijnaarts, H. and Nijmeijer, K. 2014. Impacts of NF concentrate recirculation on membrane performance in an integrated MBR and NF membrane process for wastewater treatment. Journal of membrane science, 453, 359-368.

Katayama, T. and Nitta, T. 1976. Solubilities of hydrogen and nitrogen in alcohols and n-hexane. Journal of Chemical and Engineering Data, 21, 194-196.

Kim, C. S. and Oh, S. M. 2001. Performance of gel-type polymer electrolytes according to the affinity between polymer matrix and plasticizing solvent molecules. Electrochimica acta, 46, 13231331.

Koros, W., Fleming, G., Jordan, S., Kim, T. and Hoehn, H. 1988a. Polymeric membrane materials for solution-diffusion based permeation separations. Progress in Polymer Science, 13, 339-401.

Koros, W. J., Fleming, G. K., Jordan, S. M., Kim, T. H. and Hoehn, H. H. 1988b. Polymeric membrane materials for solution-diffusion based permeation separations. Progress in Polymer Science, 13, 339-401.

Kunthadong, P., Molloy, R., Worajittiphon, P., Leekarkpai, T., Kaabbuathong, N. and Punyodom, W. 2015. Biodegradable Plasticized Blends of Poly(L-lactide) and Cellulose Acetate Butyrate: From Blend Preparation to Biodegradability in Real Composting Conditions. Journal of Polymers and the Environment, 23, 107-113.

Lalia, B. S., Kochkodan, V., Hashaikeh, R. and Hilal, N. 2013. A review on membrane fabrication: Structure, properties and performance relationship. Desalination, 326, 77-95. 
Lee, R., Jawad, Z., Ahmad, A., Ngo, J. and Chua, H. 2017. Improvement of $\mathrm{CO}_{2} / \mathrm{N}_{2}$ separation performance by polymer matrix cellulose acetate butyrate. In IOP Conference Series: Materials Science and Engineering (Vol. 206, No. 1, p. 012072). IOP Publishing.

Liu, L. F., Cai, Z. B., Shen, J. N., Wu, L. X., Hoek, E. M. and Gao, C. J. 2014. Fabrication and characterization of a novel poly (amide-urethane imide) TFC reverse osmosis membrane with chlorine-tolerant property. Journal of Membrane Science, 469, 397-409.

Liu, Y., Wang, R. and Chung, T. S. 2001. Chemical cross-linking modification of polyimide membranes for gas separation. Journal of Membrane Science, 189, 231-239.

Low, B. T., Zhao, L., Merkel, T. C., Weber, M. and Stolten, D. 2013. A parametric study of the impact of membrane materials and process operating conditions on carbon capture from humidified flue gas. Journal of Membrane Science, 431, 139-155.

Lui, A., Talbot, F., Fouda, A., Matsuura, T. and Sourirajan, S. 1988. Studies on the solvent exchange technique for making dry cellulose acetate membranes for the separation of gaseous mixtures. Journal of applied polymer science, 36, 1809-1820.

Matsuyama, H., Kim, M. M. and Lloyd, D. R. 2002. Effect of extraction and drying on the structure of microporous polyethylene membranes prepared via thermally induced phase separation. Journal of Membrane Science, 204, 413-419.

Ohya, H., Akimoto, N. and Negishi, Y. 1980. Reverse osmosis separation characteristics of organic solutes with cellulose acetate butyrate membranes. 5, 179-184.

Ong, R. C., Chung, T. S., Helmer, B. J. and De Wit, J. S. 2012. Novel cellulose esters for forward osmosis membranes. Industrial and engineering chemistry research, 51, 16135-16145.

Radjabian, M., Koll, J., Buhr, K., Vainio, U., Abetz, C., Handge, U. A. and Abetz, V. 2014. Tailoring the morphology of self-assembled block copolymer hollow fiber membranes. Polymer, 55, 2986-2997.

Rahimpour, A., Madaeni, S., Taheri, A. and Mansourpanah, Y. 2008. Coupling $\mathrm{TiO}_{2}$ nanoparticles with UV irradiation for modification of polyethersulfone ultrafiltration membranes. Journal of Membrane Science, 313, 158-169.

Pandey, P. and Chauhan, R.S., 2001. Membranes for gas separation. Progress in Polymer Science, 26(6), pp.853-893.

Paradise, M. and Goswami, T. 2007. Carbon nanotubes - Production and industrial applications. Materials and Design, 28, 1477-1489.

S.Minhas, B. 1992. Cellulose Acetate Butyrate Gas Separation Membranes.U.S. Patent 5,096,468.

Sabde, A. D., Trivedi, M., Ramachandhran, V., Hanra, M. and Misra, B. 1997. Casting and characterization of cellulose acetate butyrate based UF membranes. Desalination, 114, 223-232.

Scholes, C. A., Stevens, G. W. and Kentish, S. E. 2012. Membrane gas separation applications in natural gas processing. Fuel, 96, 15-28.

Shekhawat, D. 2003. A review of carbon dioxide selective membranes. US department of energy, 9-11.

Suttiwijitpukdee, N., Sato, H., Zhang, J., Hashimoto, T. and Ozaki, Y. 2011. Intermolecular interactions and crystallization behaviors of biodegradable polymer blends between poly (3hydroxybutyrate) and cellulose acetate butyrate studied by DSC, FT-IR, and WAXD. Polymer, 52, 461-471.

Thomas, R., Guillen-Burrieza, E. and Arafat, H. A. 2014. Pore structure control of PVDF membranes using a 2-stage coagulation bath phase inversion process for application in membrane distillation (MD). Journal of Membrane Science, 452, 470-480. 
Tiraferri, A., Yip, N. Y., Phillip, W. A., Schiffman, J. D. and Elimelech, M. 2011. Relating performance of thin-film composite forward osmosis membranes to support layer formation and structure. Journal of Membrane Science, 367, 340-352.

Wan, Y., Creber, K. A., Peppley, B. and Bui, V. T. 2004. Structure and ionic conductivity of a series of di-o-butyrylchitosan membranes. Journal of applied polymer science, 94, 2309-2323.

Wan, Y., Creber, K. A. M., Peppley, B. and Bui, V. T. 2003. Ionic conductivity of chitosan membranes. Polymer, 44, 1057-1065.

Wang, Y., Lau, W. W. and Sourirajan, S. 1994. Effects of membrane-making conditions and shrinkage treatment on morphology and performance of cellulose acetate butyrate membranes. Separation science and technology, 29, 1689-1704.

Xia, S. and Ni, M. 2015. Preparation of poly (vinylidene fluoride) membranes with graphene oxide addition for natural organic matter removal. Journal of Membrane Science, 473, 54-62.

Xin, Q., Gao, Y., Wu, X., Li, C., Liu, T., Shi, Y., Li, Y., Jiang, Z., Wu, H. and Cao, X. 2015. Incorporating one-dimensional aminated titania nanotubes into sulfonated poly (ether ether ketone) membrane to construct $\mathrm{CO}_{2}$-facilitated transport pathways for enhanced $\mathrm{CO}_{2}$ separation. Journal of Membrane Science, 488, 13-29.

Xu, Z., Zhang, J., Shan, M., Li, Y., Li, B., Niu, J., Zhou, B. and Qian, X. 2014. Organosilanefunctionalized graphene oxide for enhanced antifouling and mechanical properties of polyvinylidene fluoride ultrafiltration membranes. Journal of Membrane Science, 458, 1-13.

Yang, H., Xu, Z., Fan, M., Gupta, R., Slimane, R. B., Bland, A. E. and Wright, I. 2008. Progress in carbon dioxide separation and capture: A review. Journal of Environmental Sciences, 20, 1427.

Yang, Y. and Wang, P. 2006. Preparation and characterizations of a new $\mathrm{PS} / \mathrm{TiO}_{2}$ hybrid membranes by sol-gel process. Polymer, 47, 2683-2688.

Yave, W., Car, A., Funari, S. S., Nunes, S. P. and Peinemann, K. V. 2009. $\mathrm{CO}_{2}$-philic polymer membrane with extremely high separation performance. Macromolecules, 43, 326-333.

Zha, S., Yu, J., Zhang, G., Liu, N. and Lee, R. 2015. Polyethersulfone (PES)/cellulose acetate butyrate (CAB) composite hollow fiber membranes for BTEX separation from produced water. RSC Advances, 5, 105692-105698.

Zhu, W. P., Sun, S. P., Gao, J., Fu, F. J. and Chung, T. S. 2014. Dual-layer polybenzimidazole/polyethersulfone (PBI/PES) nanofiltration (NF) hollow fiber membranes for heavy metals removal from wastewater. Journal of Membrane Science, 456, 117-127. 